\title{
Working
}

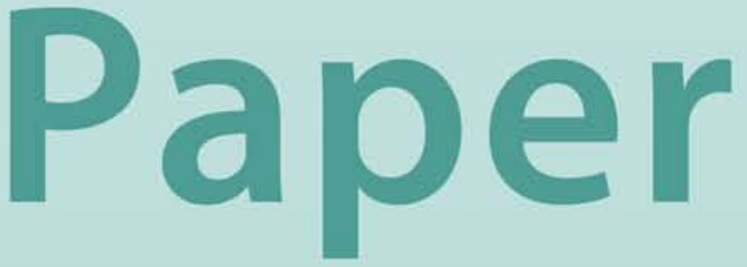




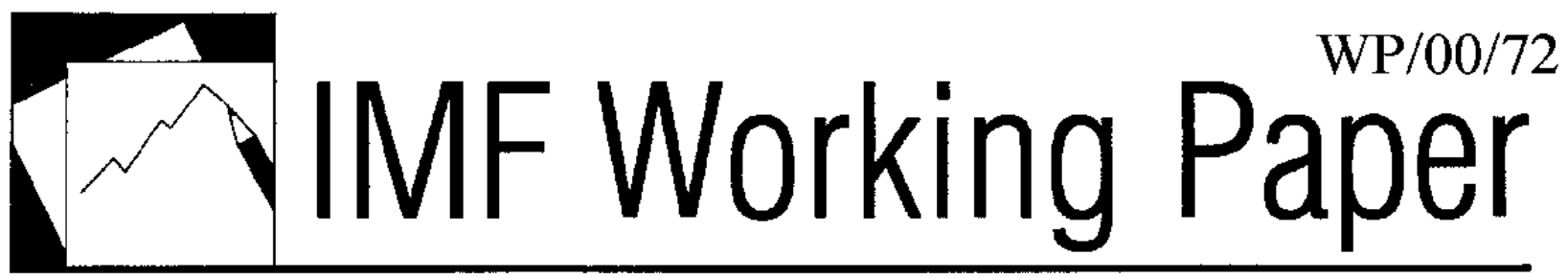

Terms of Trade Shocks in Africa: Are They Short-Lived or Long-Lived?

Paul Cashin and Catherine Pattillo 


\title{
IMF Working Paper
}

\author{
Research Department
}

\section{Terms of Trade Shocks in Africa: Are They Short-Lived or Long-Lived?}

Prepared by Paul Cashin and Catherine Pattillo ${ }^{1}$

Authorized for distribution by Peter Wickham and Eduardo Borensztein

April 2000

\begin{abstract}
The views expressed in this Working Paper are those of the author(s) and do not necessarily represent those of the IMF or IMF policy. Working Papers describe research in progress by the author(s) and are published to elicit comments and to further debate.
\end{abstract}

This paper examines the persistence of shocks to the terms of trade, using annual data on 42 Sub-Saharan African countries between 1960-96. We find that the persistence of terms of trade shocks varies widely - for about half the countries such shocks are short-lived, while for one-third of the countries such shocks are long-lived. The countries experiencing long-lived terms of trade shocks are typically those that have large shares of petroleum imports in total imports, small shares of nonfuel commodity exports in total exports, and are highly concentrated in exportable commodities with long-lived price shocks.

JEL Classification Numbers: C22, F41, 013, Q17

Keywords: Terms of Trade, Shock Persistence, Sub-Saharan Africa

Authors’ E-Mail Addresses: Pcashin@imf.org; cpattillo@imf.org

\footnotetext{
'We thank Michael Bleaney, John McDermott, Sam Ouliaris, Eswar Prasad, Peter Wickham and seminar participants at the IMF for valuable comments and suggestions. Nada Mora, Grace Juhn and Ivan Guerra provided excellent research assistance.
} 


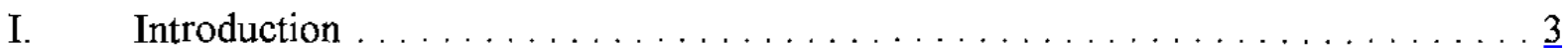

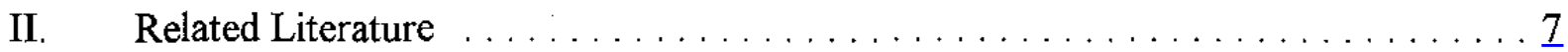

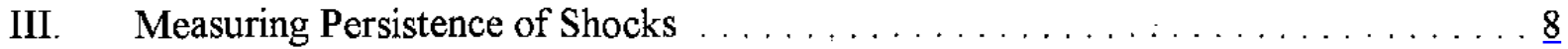

IV. Data and Empirical Results .......................... 11

A. Commodity or Net Barter Terms of Trade - Which is the More Appropriate Relative Price Measure? . . . . . . . . . . . . . . . . . . . . . 12

B. Persistence of Shocks to the Net Barter Terms of Trade ......... 16

C. Size of Shocks to the Net Barter Terms of Trade .............. 22

D. Persistence of Shocks to the Income Terms of Trade . . . . . . . . . 22

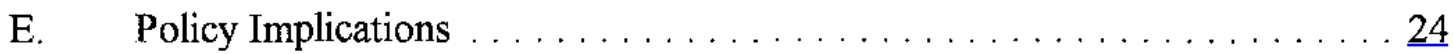

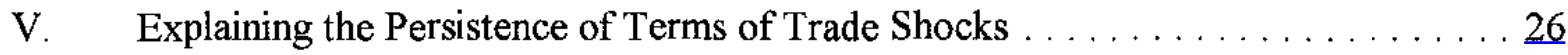

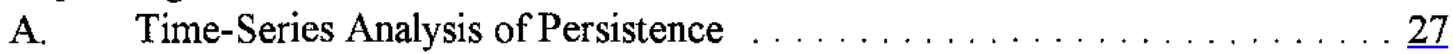

B. Cross-Sectional Analysis of Persistence $\ldots \ldots \ldots \ldots \ldots \ldots \ldots \ldots \ldots \ldots \ldots \ldots$

VI. Conclusion ........................

Tables:

1. Main Exports of Sub-Saharan African Countries, $1990 \ldots \ldots \ldots \ldots \ldots$. . . . . . 4

2. African Countries Dependent on a Single Primary Commodity for Export Earnings . 5

3. Persistence of Shocks to the Net Barter Terms of Trade, Sub-Saharan Africa,

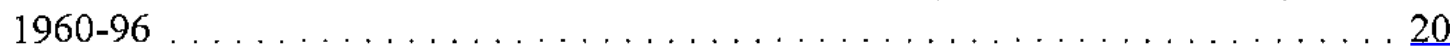

4. Persistence of Shocks to the Income Terms of Trade, Sub-Saharan Africa,

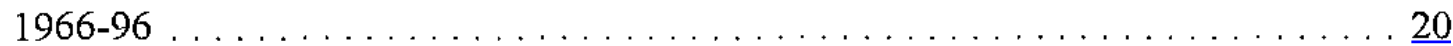

5. Explaining the Persistence of Shocks to African Countries' Net

Barter Terms of Trade ..............................

Figures:

1. Net Barter Terms of Trade, Sub-Saharan Africa, 1960-96 $(1987=100) \ldots \ldots \ldots \underline{13}$

2. Median Duration (Half-Life) of Shocks to the Net Barter Terms of Trade,

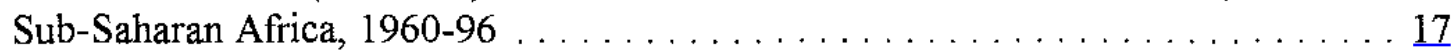

3. Size of Shocks to the Net Barter Terms of Trade, Sub-Saharan Africa, 1960-96 . . 223

4. Net Barter Terms of Trade Shock Persistence and Country Characteristics ...... 31

5. Net Barter Terms of Trade Shock Persistence and Country Characteristics . . . . . $\underline{32}$

Appendices:

I. Descriptive Statistics, Net Barter Terms of Trade, Sub-Saharan Africa, 1960-96 . $\underline{38}$

II. Results of Median-Unbiased Autoregressive/Unit Root Estimation, Net Barter

Terms of Trade, Sub-Saharan Africa, $1960-96 \ldots \ldots \ldots \ldots \ldots \ldots \ldots .40$

III. Persistence of Terms of Trade Shocks - Case Study of Uganda . . . . . . . . 43

IV. Persistence of Terms of Trade Shocks-Alternative Data ............. 44

V. Cointegration and Unit Root Tests, Export and Import Price Indices,

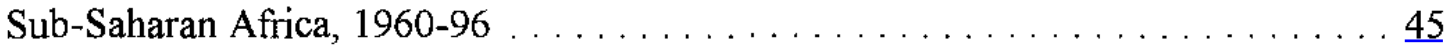

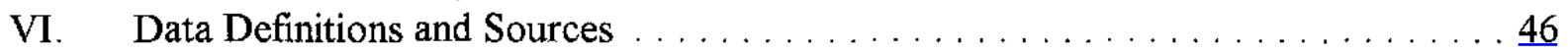

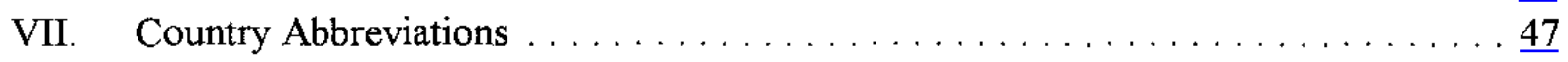

References ............................. 48 


\section{INTRODUCTION}

A country's terms of trade is one of the most important relative prices in economics, yet economists are largely ignorant of many of its empirical properties. The ratio of an index of a country's export prices to the prices of its imported goods defines the net barter terms of trade (NBTT), which measures the number of units of imports that can be exchanged for a unit of exports. Particularly for commodity-exporting developing countries, movements in the NBTT are key determinants of a country's macroeconomic performance, and have an important impact on real national incomes. For example, arabica coffee is the dominant exportable of Ethiopia. The slump in world arabica coffee prices in 1986-87, largely caused by world production in excess of consumption, resulted in a 40 percent fall in Ethiopia's terms of trade. As imports were about 15 percent of its national expenditure, this adverse movement in its terms of trade resulted in about a 6 percent decline in Ethiopia's real income. Such terms of trade-induced shocks to real incomes in developing countries necessitate a domestic policy response, but in framing an appropriate response, an important question is how long-lasting are typical shocks?

This paper examines the persistence of shocks to the net barter and income terms of trade for 42 Sub-Saharan African (SSA) countries. SSA's exports are overwhelmingly comprised of primary commodities, while food items, oil and manufactured goods are the major imports (Tables 1 and 2). The goal of this paper is to estimate the duration of shocks to the terms of trade for SSA countries, and to provide some explanation for the differences in shock persistence across countries. While there are numerous papers on trends in real commodity prices, and some work has been carried out on price trends in the important exports of developing countries, there has been very little research which examines the persistence of shocks to a country's terms of trade. If terms of trade shocks are typically short-lived, there may be scope for changes in domestic saving, or (given access to foreign capital) for international borrowing and lending to smooth the path of national consumption. However, if terms of trade shocks are typically long-lived, then counter-cyclical policies have little chance of success and countries should adjust to the new equilibrium.

SSA's export performance has deteriorated steadily since the early 1970 s, with some improvements recorded since 1993. Although debated, the level and trend of the NBTT have not been identified as a major factor explaining Africa's dismal export performance (Svedberg (1991)). It has been argued, however, that African governments have handled terms of trade shocks extremely badly, and that an inability to cope with external shocks has contributed to Africa's debt problems and very low rate of economic growth. This mishandling has led to small gains from positive shocks, while the real losses from negative shocks have been large. Many governments responded to commodity price booms in the late 1970 s by sharply expanding public expenditure for hastily-executed, import-intensive public investment programs that they either abandoned or financed with foreign borrowing when revenues fell with subsequent steep declines in commodity prices. For example, several countries dependent on minerals which experienced price declines in the 1970s - such as copper in Zaire and Zambia and iron ore in Liberia and Mauritania - undertook large external borrowing on the assumption that these negative price shocks were short-lived. 
Table 1. Main Exports of Sub-Saharan African Countries, 1990

\begin{tabular}{|c|c|c|}
\hline Country & $\begin{array}{l}\text { Total Share of } 25 \\
\text { Commudities } 1 /\end{array}$ & $\begin{array}{l}\text { Share of all Exports } \\
\text { in GDP }\end{array}$ \\
\hline Angola & 93 & 39 \\
\hline Benin & 65 & 22 \\
\hline Botswana & 93 & 56 \\
\hline Burkina Faso & 78 & 13 \\
\hline Burundi & 85 & 8 \\
\hline Cameroon & 88 & 20 \\
\hline Central African Rep. & 81 & 15 \\
\hline Chad & 85 & 19 \\
\hline Congo, Dem. Rep. & 84 & 9 \\
\hline Congo & 85 & 51 \\
\hline Côte đ'Ivoire & 54 & 32 \\
\hline Equatorial Guinca & 35 & 28 \\
\hline Ethiopia & 57 & 8 \\
\hline Gabon & 48 & 46 \\
\hline Gambia & 48 & 69 \\
\hline Ghana & 85 & 17 \\
\hline Guinea & 93 & 31 \\
\hline Guinea Bissau & 56 & 11 \\
\hline Kenya & 51 & 26 \\
\hline Liberia & 33 & 43 \\
\hline Madagascar & 38 & 16 \\
\hline Malawi & 90 & 24 \\
\hline Mali & 64 & 17 \\
\hline Mauritania & 91 & 46 \\
\hline Mauritius & 34 & 65 \\
\hline Mozambique & 57 & 16 \\
\hline Niger & 87 & 17 \\
\hline Nigeria & 98 & 43 \\
\hline Rwanda & 88 & 6 \\
\hline Senegal & 67 & 27 \\
\hline Sierra Leone & 38 & 24 \\
\hline Sudan & 44 & 7 \\
\hline Swaziland & 27 & 83 \\
\hline Tanzania & 71 & 13 \\
\hline Togo & 78 & 33 \\
\hline Uganda & 83 & 72 \\
\hline Zambia & 89 & 36 \\
\hline Zimbabwe & 49 & 32 \\
\hline
\end{tabular}

Source: Deaton (1999).

1/ Share of 25 is the total share in 1990 export value of the following 25 commoditics: aluminum, bauxite, cocoa, coffee, copper, cotton, diamonds, fish, gold, groundnut oil, groundnuts, iron, manganese, nickel, oil, phosphates, palm oil, palm kernels, rubber, sisal, sugar, tea, tobacco, uranium, wood and wood products. 
Table 2. African Countries Dependent on a Single Primary Commodity for Export Earnings

(Annual average of export data, U.S. dollars, 1992-97)

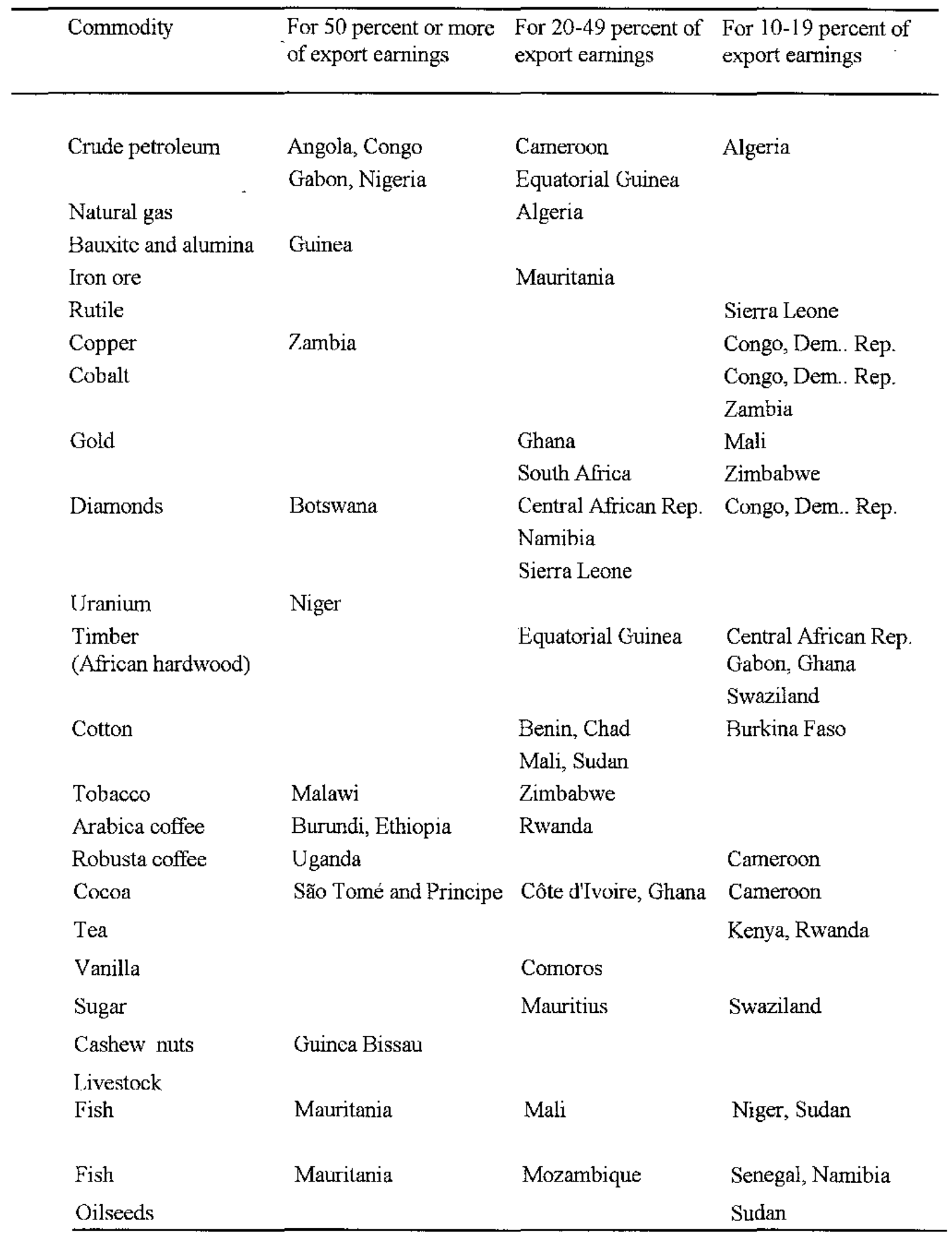

Source: Cashin, Liang and McDermott (1999), and International Monetary Fund. 
Two recent studies challenge parts of the conventional wisdom that commodity price booms in Africa are generally harmful. The approach and findings of Collier and Gunning (1999) and Deaton and Miller (1996) differ in many respects. Both studies agree, however, that the difficulty in predicting the duration of a shock is a constraint on the ability of African policy-makers to manage commodity price shocks. In light of what Deaton and Miller see as insurmountable problems in reliably forecasting commodity prices, they recommend that countries adopt simple policy rules, such as making fundamental adjustments to all price shocks, unless they can be unambiguously identified as temporary.

The same difficulties are involved in assessing the duration of shocks to the NBTT. Is it possible to provide more useful estimates that may allow for a deviation from the DeatonMiller rule? One problem with the traditional approach to the characterization of the properties of the NBTT series is the dependence on unit root tests. Series are either modeled as trend-stationary, where innovations in prices have no permanent effects, or differencestationary, implying that shocks have permanent effects. In addition to the inherent difficulties in distinguishing between the two processes (Deaton (1992)), this method does not provide a measure of the uncertainty of the estimates of finiteness or permanence of innovations. In contrast to this stark dichotomy between finite and permanent effects of shocks to the NBTT, in this paper we calculate the length of time typically taken for the effects of NBTT shocks to dissipate. In addition, we calculate confidence intervals for the estimated duration of the shock, where the width of the confidence interval indicates the certainty with which shock persistence is estimated.

The contributions of this paper are fourfold. First, we use the median-unbiased estimator proposed by Andrews (1993) to obtain an exact point and interval estimate of the autoregressive parameter in the terms of trade data. This econometric procedure is superior to the results emanating from standard (least squares) unit root regressions, as least squares estimates are biased and conventional unit root tests typically have low power. While there is little that can be done to improve the power of unit root tests, an interval estimate of the autoregressive parameter does yield useful information as to whether a failure to reject the null hypothesis of a unit root is due to the null being true or due to the uncertainty of the estimate of the autoregressive parameter. Second, using unbiased estimates of the autoregressive parameter we calculate scalar measures of the duration (in terms of the number of periods) of typical NBTT shocks, and the exact confidence interval surrounding the estimated median duration of shocks.

Third, unlike earlier studies we focus our attention on the duration of shocks to the terms of trade of individual countries, rather than use the price of agricultural commodities relative to manufactures as a proxy for the terms of trade. We find that, on average, there is a bifurcation in the duration of shocks to the NBTT, with about half the countries experiencing short-lived shocks (where it typically takes less than four years for half of the effect of the initial shock to dissipate) and one-third of the countries experiencing long-lived shocks (where shocks are permanent). In addition, the confidence intervals surrounding the estimated median duration of shocks are typically quite wide, indicating that the persistence of terms of trade shocks is rather variable in length. 
Fourth, we provide some explanations for cross-country differences in the persistence of shocks to their NBTT. Most countries are found to have finitely-persistent shocks to their NBTT, and a finding of finite persistence implies that export and import prices should be cointegrated. While this is confirmed for some countries, for many countries there is evidence of instability in the linear relationship between export and import prices, which could account for the difficulties in establishing cointegration. As to explanations for the differences in shock persistence across countries, using cross-country regressions we find that terms of trade shocks tend to last longer for countries with large shares of petroleum imports in total imports, with small shares of nonfuel commodity exports in total exports, and which are highly concentrated in exportable commodities with long-lived price shocks.

The remainder of the paper is organized as follows. Section II examines previous work on the properties of the terms of trade, while Section III sets out a median-unbiased estimator of first-order autoregressive/unit root (AR/UR) models, and its advantages as a measure of the persistence of shocks to economic time series. Section IV describes the data used in the study, and presents the main empirical findings regarding the persistence of shocks to the net barter and income terms of trade for 42 countries of Sub-Saharan Africa during the period 1960 to 1996. Time-series and cross-sectional analyses of the determinants of the heterogeneous duration of terms of trade shocks are given in Section V. Some concluding comments are contained in Section VI.

\section{RELATED LITERATURE}

The bulk of the literature analyzing the properties of the terms of trade focuses on trends in the relative price commonly referred to as the commodity terms of trade (the price of primary commodities relative to manufactured goods). Few hypotheses in development economics have been studied more intensively than the famous Prebisch-Singer hypothesis, which postulates a secular negative trend in the prices of internationally-traded primary commodities relative to those of manufactured products. ${ }^{2}$ In addition, there have also been a few studies that looked specifically at whether there has been a sustained decline in the NBTT of African countries (Osei (1999) and Svedberg (1991)). While the presence or absence of secular trends in the commodity or NBTT is an important issue, of equal importance for policymakers is the issue of the persistence of shocks to the terms of trade. While some work has been done on the persistence of shocks to the commodity terms of trade (Cashin, Liang and McDermott (1999), León and Soto (1997)), there has been virtually no work done on the persistence of shocks to the NBTT of particular countries.

\footnotetext{
${ }^{2}$ See Prebisch (1950) and Singer (1950), and more recently Grilli and Yang (1988), Cuddington and Urzúa (1989), Powell (1991), and León and Soto (1997), among many others.
} 
In a study of the relationship between terms of trade and business cycles for a set of industrial and developing countries, Mendoza (1995) measures terms of trade persistence by first-order serial correlation of the Hodrick-Prescott filtered time series. He finds that terms of trade shocks are large, persistent and account for close to one-half of the variability of GDP. The terms of trade of African countries have the highest autocorrelation among the developing country regions, although the autocorrelation is slightly higher for industrialized countries.

We are aware of only one paper specifically focusing on the persistence of shocks to the terms of trade of individual countries. León and Soto (1995) implement Cochrane's (1988) non-parametric estimator, which measures the fraction of a price shock that will persist into the indefinite future. They use terms of trade data for 16 Latin American countries during the period 1928-1993, and find that shocks to the terms of trade are permanent (have infinite persistence) in only five countries, while in the others the shocks revert to a deterministic trend. In the latter cases, while the reversion is significant during the first five years, the process continues more slowly afterward, so that it takes 20 to 25 years to return to long-run equilibrium.

There are a number of weaknesses of the non-parametric estimator, such as the fact that in small samples the permanent component of the variance is biased upward (Cochrane (1988)). The greater drawback is that while the non-parametric approach provides

information on the share of the long-run variance in total variance of terms of trade shocks, such information is of limited use to policy makers in determining how to respond to shocks. The key question for policy makers concerns the typical duration of price shocks. In contrast, the approach used in this paper to measure persistence does enable the calculation of unbiased scalar measures of the duration and variability of typical terms of trade shocks.

\section{Measuring Persistence of Shocks}

The median-unbiased estimation procedure proposed by Andrews (1993), rather than unit root tests, is used to determine the persistence of shocks to the terms of trade. Standard unit root testing procedures (such as those of Dickey and Fuller (1979) and Phillips and Perron (1988)) suffer from two main disadvantages: (i) the least squares estimates of the autoregressive parameter in unit root regressions will be biased toward zero (Orcutt (1948)); and (ii) they have low power against plausible trend-stationary alternatives (DeJong et al. (1992)). The downward bias in least squares estimates of the autoregressive parameter arises because there is an asymmetry in the distribution of estimators of the autoregressive parameter in AR/UR models (the distribution is skewed to the left, resulting in the median exceeding the mean). As result, the median is a better measure of central tendency than the mean in least squares estimates of AR/UR models. If standard unit root tests fail to correctly reject the null, then, because of low power problems, nothing can be confidently implied about the persistence of shocks to the series.

The median-unbiased estimator of Andrews combines unbiasedness with the use of point and interval estimators in achieving a more accurate estimate of the persistence of 
shocks to economic time series. Interval estimation addresses the low power issue by informing us whether we are failing to reject the null because it is true or because there is too much uncertainty. The bias correction delivers an impartiality property to the decision making process, because there is an equal chance of under- or over-estimating the autoregressive parameter in the unit root regression, and thus the probability of selecting the correct model is at least as large as the probability of selecting the incorrect model. Moreover, an unbiased estimate of the autoregressive coefficient will allow us to calculate an unbiased estimate of the persistence of shocks. ${ }^{3}$

The Andrews (1993) median-unbiased estimator is concerned with the estimation of first-order AR/UR models with independent identically distributed normal errors. The model of the time series $\left\{Y_{t}: t=0, \ldots, T\right\}$ considered is that which includes an intercept and time trend: ${ }^{4}$

$$
\begin{gathered}
Y_{t}=\mu^{*}+\alpha Y_{t-1}+\beta^{*} t+\epsilon_{t} \text { for } t=1, \ldots, T, \\
\text { where } \mu^{*}=\mu(1-\alpha)+\alpha \beta, \beta^{*}=\beta(1-\alpha), \text { and } \alpha \in(-1,1]
\end{gathered}
$$

where $\epsilon_{t}$ are the innovations of the model, $\mu$ is the intercept and $t$ is the trend.

To calculate the median-unbiased estimator, suppose $\hat{\alpha}$ is an estimator (of the autoregressive parameter, $\alpha$ ) whose median function $(m(\alpha))$ is uniquely defined $\forall \alpha \in(-1,1]$, then $\hat{\alpha}_{u}$ (the median unbiased estimator of $\alpha$ ) is defined as:

$$
\hat{\alpha}_{u}=\left\{\begin{array}{l}
1 \text { if } \hat{\alpha}>m(1) \\
m^{-1}(\hat{\alpha}) \text { if } m(-1)<\hat{\alpha} \leq m(1), \\
-1 \text { if } \hat{\alpha} \leq m(-1)
\end{array}\right.
$$

where $m(-1)=\lim _{\alpha \rightarrow-1} m(\alpha)$, and $m^{-1}:(m(-1), m(1)] \rightarrow(-1,1]$ is the inverse function of $m($.$) that$ satisfies $m^{-1}(m(\alpha))=\alpha$ for $\alpha \in(-1,1]$. That is, if we have a function that for each true value of $\alpha$ yields the median value of $\hat{\alpha}$, then we can simply use the inverse function to obtain a median unbiased estimate of $\alpha$. For example, if the least squares estimate of $\alpha$ equals 0.8 then we do not use that estimate, but instead use that value of $\alpha$ which results in the least squares

${ }^{3}$ The extension of these median-unbiased procedures to $p$ th-order processes is considered in Andrews and Chen (1994); for $\operatorname{AR}(p)$ models the procedures are no longer exact, only approximate. Unbiased unit root tests have been previously developed by Stock (1991) and Rudebusch (1992), both for $p$ th-order autoregressive processes with a time trend. See Andrews and Chen (1994) for a description of how these tests compare and contrast with the median-unbiased procedures.

${ }^{4}$ In equation (1), $\epsilon_{i}$ iid $N\left(0, \sigma^{2}\right)$ for $\sigma^{2}>0, Y_{0} \sim N\left(\mu, \sigma^{2} /\left(1-\alpha^{2}\right)\right)$ if $\alpha \in(-1,1)$, and $Y_{0}$ is an arbitrary constant or random variable if $\alpha=1$. 
estimator having a median of $0.8 .^{56}$ In addition, using the 0.05 and 0.95 quantile functions of $\hat{\alpha}$ we can construct two-sided 90 percent confidence intervals or one-sided 95 percent confidence intervals for $\alpha$. These confidence intervals can be used either to provide a measure of the accuracy of $\hat{\alpha}$, or to construct exact one- or two-sided tests of the null hypothesis that $\alpha=\alpha_{0}$. In this paper we use confidence intervals only to provide a measure of the accuracy of $\hat{\alpha}{ }^{7}$

The median, 0.05 quantile (lower band) and 0.95 quantile (upper band) of the function $m(\alpha)$ for the AR/UR model without and with constants and time trends has been computed for various sample sizes up to $T+1=200$ in Andrews (1993, Tables I-III), and extended for sample sizes of up to $T+1=500$ by Cashin, Liang and McDermott (1999). For sample sizes not given in either of these sources, $m(\alpha)$ can be obtained by interpolation. To illustrate the use of the tables, consider the least squares estimator for the model in equation (1), and sample size $T+1=40$ (see Andrews (1993), Table III). Suppose the least squares estimate of the autoregressive parameter from a unit root regression is 0.494 , then the median estimate is 0.60 , the 0.05 quantile is 0.93 , and the 0.95 quantile is $0.34(0.494$ is 38 percent of the way between 0.463 and 0.544 , therefore we choose 38 percent of the way between 0.30 and 0.40 , which is 0.338$)$. Thus the two-sided 90 percent confidence interval is $(0.34,0.93)$.

Our interest in this paper concerns the persistence of shocks to economic time series. The measures we will use to quantify this persistence are the impulse response function (IRF), the cumulative impulse response function (CIR), and the half-life of a unit shock (HLS). The IRF of a time series $\left\{Y_{t}: t=1,2, \ldots\right\}$ measures the effect of a unit shock occurring at time $t$ (that is, $\epsilon_{t} \rightarrow \epsilon_{t}+1$ in equation (1)) on the values of $Y_{t}$ at the future time periods $t+1, t+2, \ldots$ The IRF quantifies the persistence of shocks to individual time series. For a series with a unit root the IRF never dies out; however, for a trend-stationary series the IRF does die out. In any event, whether an individual time series is trend stationary or has a unit root, the relative magnitude of the IRF across different time horizons indicates the extent of the persistence of shocks to the individual series. The IRF is defined as

$$
\operatorname{IRF}(\tau)=\alpha^{\tau} \quad \text { for } \tau=0,1,2, \ldots
$$

\footnotetext{
${ }^{5}$ If the distribution of the least squares estimator of $\alpha$ depends only on $\alpha$ and is monotone in $\alpha$ (as in the AR(1) case), then the resultant estimator will have the property of median unbiasedness (Andrews (1993)).

${ }^{6}$ The size of the bias correction can be large, especially when $\alpha$ is close to one. For example, for a sample size of 60 observations using the model in equation (1), a least squares estimate of $\alpha=0.85$ or greater would correspond to a median-unbiased estimate of $\alpha=1$; that is, $m(1)=0.85$.

${ }^{7}$ When conducting the unit root test (null hypothesis that $\alpha=1$ ) we prefer to use an unbiased model selection rule rather than the confidence interval. Such a rule recommends choosing a unit root model when the median unbiased estimate of $\alpha$ equals 1 , and choose a trend stationary model if the median unbiased estimate of $\alpha$ is less than 1 .
} 
Rather than consider the whole IRF, Andrews (1993) provides two scalar measures of persistence that summarize the impulse response function: the cumulative impulse response (CIR) and the half-life of a unit shock (HLS). Whereas the CIR gives the total cumulative effect of a unit shock on the entire future of a time series (that is, the sum of the IRF over all time horizons), for $\alpha \geq 0$ the HLS gives the length of time until the impulse response of a unit shock is half its original magnitude. These measures are defined as

$$
C I R=\sum_{\tau=0}^{\infty} I R F(\tau)=(1-\alpha)^{-1} \text { and } H L S=A B S(\log (1 / 2) / \log (\alpha)) \text {. }
$$

Exactly median-unbiased estimators and exact confidence intervals are also calculated for the IRF, CIR and HLS, which provide information on the variability of the scalar measures of persistence. The median-unbiased estimate for these measures of persistence is calculated by using the median-unbiased estimate of $\alpha$ in the formulae of equation (4). Similarly, the twosided 90 percent confidence interval is calculated using the 0.05 and 0.95 quantiles in the formulae of equation (4). ${ }^{8}$

\section{Data AND EMpirical Results}

We use annual terms of trade data for the period 1960 to 1996, for 42 Sub-Saharan African countries taken from the indices provided by the World Bank from its World Development Indicators database. The data are for the NBTT (an index number formed as the price index of exports of goods divided by the price index of imports of goods) and the income terms of trade (YTT, which is the NBTT index multiplied by the index of the volume of exports), with both the indices of NBTT and export volume having base year 1987. The data are expressed in logarithmic form. ${ }^{9}{ }^{10}$

${ }^{8}$ These median-unbiased measures can be compared with least squares estimators of persistence and associated confidence intervals, where the least squares estimates will (given they are functions of a downwardly-biased $\alpha$ ) tend to understate the actual amount of persistence in shocks to economic time series (see Section IV and Appendix II).

${ }^{9}$ In fact, while the YTT (denoted by the World Bank as exports as a capacity to import) are available in the WDI database, the NBTT are no longer included in the 1998 edition of the database. The World Bank obtains the terms of trade data from the United Nations Conference on Trade and Development's (UNCTAD) publication Handbook of International Trade and Development Statistics and does publish it in the World Development Indicators volume (previously World Tables). Thus, we obtained the NBTT data from a file sent by the World Bank Data group and from various issues of these published sources.

${ }^{10}$ The countries in our sample are listed in Appendix II. The data for all countries run from 1960-96, all with base year 1987=100, excepting: Botswana, Burundi, Comoros, Equatorial Guinea, Guinea, Guinea-Bissau, São Tomé and Principe, Seychelles, South Africa, and Zimbabwe (all 1970-93). 
As to descriptive statistics of the NBTT data, for most of the series there is little evidence of significant skewness, as for all but ten countries (Botswana, Cameroon, Congo, Côte d'Ivoire, Gabon, Guinea-Bissau, Madagascar, Mauritius, Nigeria and Togo) the null hypothesis of zero skewness is not rejected. The widespread absence of skewness indicates that there is little evidence in support of trends in the NBTT. Similarly, only ten of the 42 countries (Angola, Botswana, Cameroon, Congo, Côte d'Ivoire, Gabon, Liberia, Nigeria, Togo and Uganda) display significant leptokurtosis, with tails of their distribution much thicker than those of the normal distribution (see Appendix I) ${ }^{11}$ The widespread absence of leptokurtosis indicates that big shocks to the NBTT are relatively infrequent events. In short, for most countries the distribution of NBTT is well approximated by the normal distribution.

Figure 1 displays the NBTT indices (base 1987=100) for the countries in our sample, grouped by region. For many of the countries the graphs show a gradual decline in the NBTT since the mid-1970s to early 1980s. For a number of Southern and Indian Ocean countries as well as Somalia and Sudan, however, NBTT have fluctuated around a flat trend for most of the period. Focusing on shocks to a number of commodities that are important for many SSA countries, the figure illustrates the beverage boom of the late $1970 \mathrm{~s}-$ coffee for many East African countries and cocoa for a number West African and Sahelian countries. The NBTT for oil-exporters reflects the 1974 and 1979 oil price increases, as well as the sharp fall in oil prices in the mid-1980s. The cotton price increases of the mid-1970s and mid-1990s register for only some of the cotton-exporting countries. The copper price boom of 1964-74 is evident from Zambia's NBTT, followed by a series of shocks to a low level thereafter. The pattern for Togo is dominated by the huge phosphate boom of 1973-78. The increase in iron ore prices from 1973-81 is not reflected in Mauritania's NBTT, although some of the smaller shocks to iron ore prices later in the period are evident.

\section{A. Commodity or Net Barter Terms of Trade-Which is the More Appropriate Relative Price Measure?}

Previous work on the terms of trade has concentrated on examining the properties of the commodity terms of trade (CTT). Unlike that work, in this study we use data on each country's actual NBTT, which has been constructed using information on import and export unit values. Accordingly, and unlike the CTT index, the country-specific NBTT data do not assume that all developing countries export primary commodities and import manufactures in the same proportion as underpins the construction of the aggregate CTT index.

\footnotetext{
${ }^{11}$ These results are in contrast to those of Deaton and Laroque (1992) and Cashin, McDermott and Scott (1999), who found that skewness and excess kurtosis was commonly displayed in the prices of primary commodities. In particular, these studies found that commodity price shocks tend to be skewed toward the lower tail of the distribution (left skewness), indicating that it is likely there is a downward trend in prices for the commodity.
} 
Figure 1. Net Barter Terms of Trade, Sub-Saharan Africa, 1960-96 (1987=100)
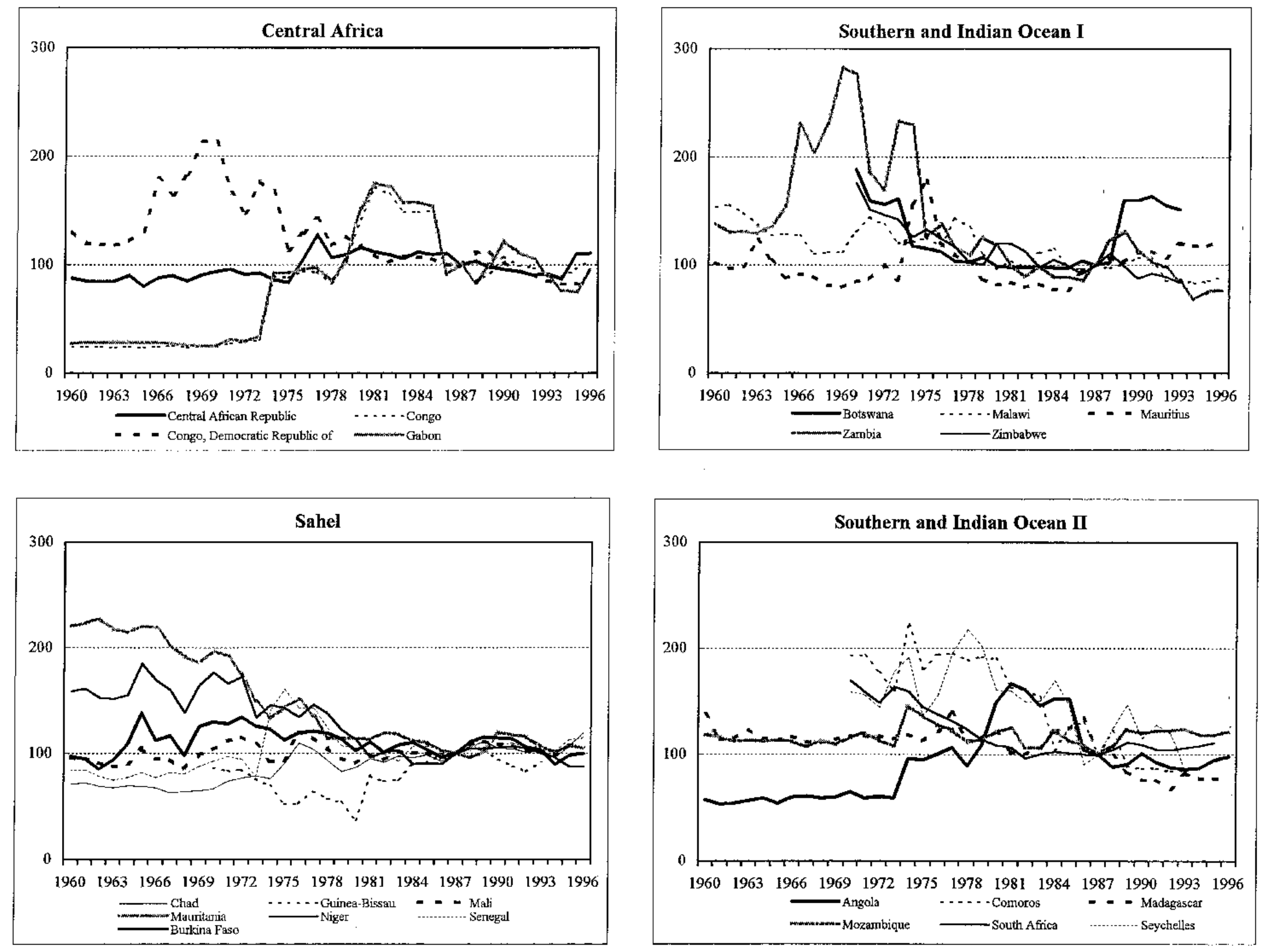
Figure 1 (Concluded). Net Barter Terms of Trade, Sub-Saharan Africa, 1960-96 (1987=100)
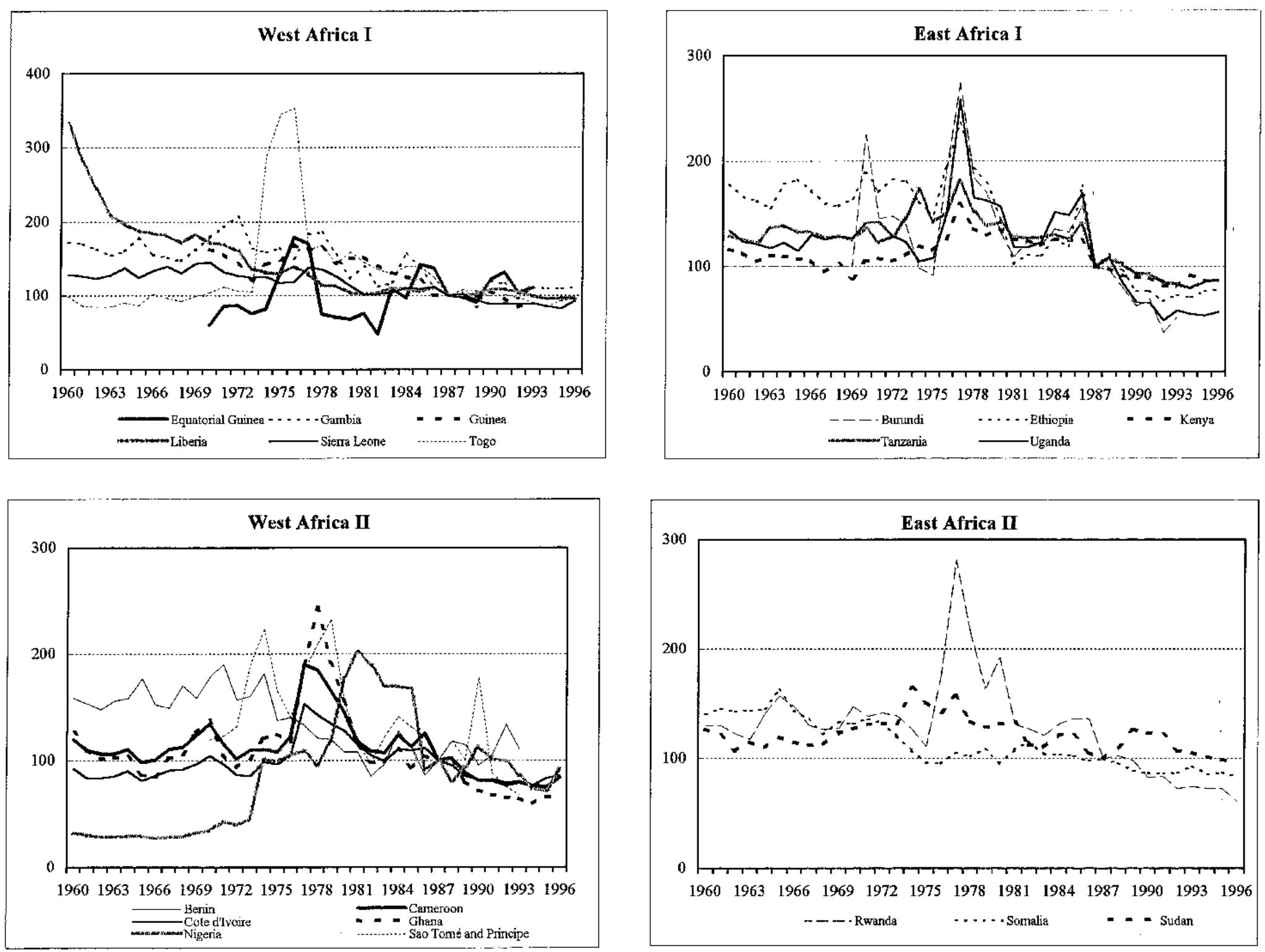

Source: World Bank, World Development Indicators 
While previous work has typically found a relationship between changes in the level of the non-oil commodity terms of trade and an aggregate index of the NBTT for non-oil developing countries as a whole (Grilli and Yang (1988), Powell (1991) and Bleaney and Greenaway (1993)), in this study such a relationship between the CTT and each country's actual NBTT was not found for almost all of the SSA countries. Using the Phillips-Perron (1988) unit root test, each country's NBTT, the CTT and the real price of oil (ROIL) were found to be nonstationary, and so the possibility of cointegration exists. ${ }^{12}$ We follow Bleaney and Greenaway (1993) in examining cointegration between the NBTT, CTT and ROL for the period 1960-96, although unlike them we replace the aggregate index of the NBTT for all developing countries with each country's NBTT.

The cointegrating relationship between each country's NBTT, CTT and ROIL was estimated using Phillips and Hansen's (1990) Fully Modified (FM) method, which yields an asymptotically correct variance-covariance estimator when estimating cointegrating vectors in the presence of serial correlation and endogeneity. The hypothesis of no cointegration can be tested using the residual-based test of Phillips and Ouliaris (1990). ${ }^{13}$ We find that the null hypothesis of no cointegration between the NBTT, CTT and ROIL is not rejected for nearly all of the 42 countries. ${ }^{14}$ In analyzing this issue further, parameter instability in the cointegrating relationship might explain our inability to find cointegration between each country's NBTT, CTT and ROIL. To examine the hypothesis of parameter stability, in the context of FM estimation of a cointegrating regression, we use the tests suggested by Hansen

\footnotetext{
${ }^{12}$ The CTT is measured as the price of nonfuel primary commodities, deflated by the index of manufactured unit values (taken from Grilli and Yang (1988) and updated to 1996 by Cashin, Liang and McDermott (2000)); ROIL is the real price of spot crude (the nominal price deflated by the index of manufactured unit values), with both nominal series taken from the IMF's $I F S$. The derivation of each country's NBTT series has been described above. All data are expressed in logarithmic form. The results of the stationarity tests are available from the authors, and were computed using the automatic bandwidth selector of Andrews (1991).

${ }^{13}$ Both the Phillips-Hansen FM estimation method and the Phillips-Ouliaris cointegration test were computed using the Fejer kernel and the automatic bandwidth selector of.Andrews (1991).

${ }^{14}$ A value of the Phillips-Ouliaris $Z(t)$ statistic (including an intercept) less than the 5 percent critical value of -3.77 (indicating a rejection of the null hypothesis of no cointegration) is not found for 36 of the 42 countries, the exceptions being Central African Republic, Chad, Kenya, Liberia, Mali and Mozambique. Very similar results are obtained when examining whether CTT and NBTT are cointegrated on their own.
} 
(1992) ${ }^{15}$ The Hansen tests of parameter stability (LC, mean-F and sup-F) indicate that there is instability in the relationship between NBTT, CTT and ROIL at the 5 percent level of significance for 36 of the 42 countries in our sample. Given the above results, an important conclusion is that there is little evidence of a long-run relationship between the aggregate CTT index and each country's NBTT, most likely because the export composition and import composition of most SSA countries bears little resemblance to the aggregate basket of exports and imports used in constructing the CTT index. Accordingly, the practice in the literature of proxying for movements in any given country's NBTT by using an aggregate index of the CTT is inappropriate, and is likely to engender misleading policy conclusions. As a result, this paper examines the persistence of shocks to each country's actual NBTT.

\section{B. Persistence of Shocks to the Net Barter Terms of Trade}

In this Section we apply the median-unbiased procedures to each country's NBTT series, as described above. The 42 NBTT series are analyzed using Andrews' (1993) model (equation (1)). Table 3 and Figure 2 set out the results for the HLS measure of the duration of shocks to the NBTT, which are based on the estimates of the autoregressive parameter set out in Appendix II. As an example of how to interpret Appendix II, we take the particular cases of Mozambique, Tanzania and Nigeria.

For Mozambique, the median-unbiased (MU) estimate of $\alpha$ is 0.486 , as opposed to the least squares (LS) estimate of 0.392 . While the difference between these two estimates is relatively small in absolute terms, this has a large effect on calculations of the persistence of the shock. The length of the 90 percent confidence interval for the median-unbiased estimate of $\alpha(0.214,0.794)$ indicates that $\alpha$ is not estimated very precisely. The IRF decline monotonically and rapidly toward zero (that is, the IRF eventually die out). The estimates yield an [LS 1.645; MU 1.944] 18 percent increase in the estimate of CIR (the total cumulative effect of a unit shock on the future evolution of the NBTT series). This indicates that a unit shock to the NBTT generates an eventual $(t=\infty) 1.944$ unit displacement of the level of the NBTT. Moreover, the time it takes for half of the impulse response of a shock to the NBTT of Mozambique to dissipate is 0.740 years for the LS estimate and 0.960 years for the MU estimate. Accordingly, shocks to the NBTT of Mozambique are not very persistent.

${ }^{15}$ The null hypothesis of the Hansen tests is that the parameters are constant. The critical values (with a constant term) at the 5 percent level of significance for the $\mathrm{LC}$, mean-F and sup-F tests are $0.69,6.17$ and 14.8 , respectively; computed values for the stability tests greater than these critical values indicate acceptance of the alternative hypothesis, which is that the parameters change at some unknown fraction of the sample. Of the six countries where the null of no cointegration between NBTT, CTT and ROL is rejected, only for the Central African Republic and Mali is the null of parameter stability also not rejected by the Hansen tests. The results of the Phillips-Ouliaris and Hansen tests for each of the 42 countries are available from the authors. 
Figure 2. Median Duration (Half-Life) of Shocks to the Net Barter Terms of Trade, Sub-Saharan Africa, 1960-96

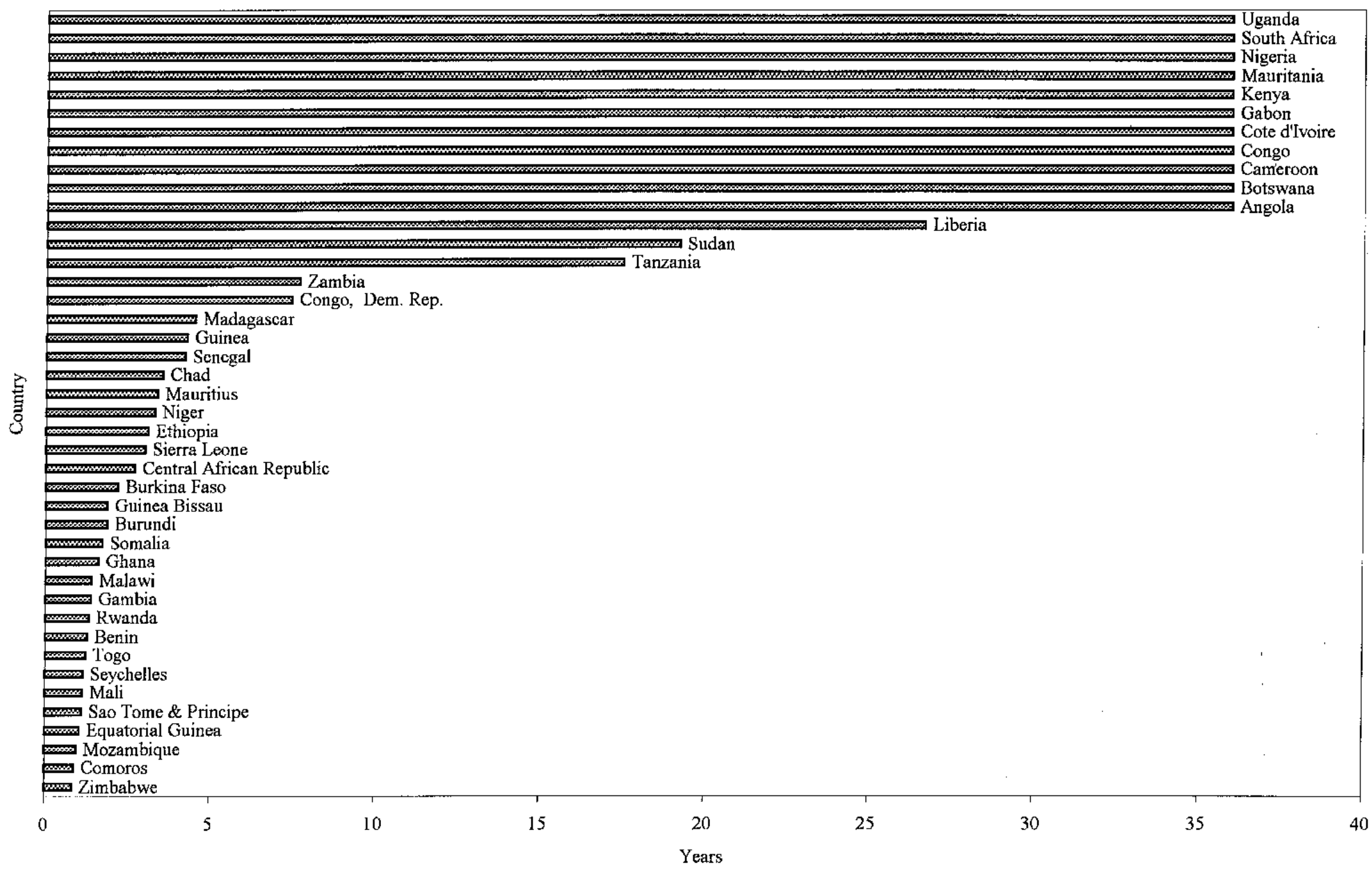

Source: Authors' calculations.

Notes: Estimated average duration (half-life) of terms of trade shocks (in years) is given by the bar chart. Those eleven countries with permanent shocks to their terms of trade have been given a half-life measure of 36 years. 
Alternatively, for Tanzania the median-unbiased estimate of $\alpha$ is 0.961 , as opposed to the least squares estimate of 0.772 . The IRF decline monotonically toward zero, yet do not die out completely. The length of the 90 percent confidence interval for the MU estimate of $\alpha(0.702,1.00)$ indicates that $\alpha$ is estimated more precisely than for Mozambique. Moreover, the LS estimate of $\alpha$ is relatively close to the lower bound of the MU estimate's 90 percent confidence interval, which indicates that Tanzania's NBTT series exhibits large differences between the LS and median-unbiased measures of persistence to shocks. The estimates yield a [LS 4.386; MU 25.821] 488 percent increase in the estimate of CIR (the total cumulative effect of a unit shock on the future evolution of the NBTT series). This indicates that a unit shock to the NBTT generates an eventual $(t=\infty) 25.821$ unit displacement of the level of the NBTT. Moreover, the time it takes for half of the impulse response of a shock to the NBTT of Tanzania to dissipate is 2.679 years for the LS estimate and 17.549 years for the MU estimate. Accordingly, shocks to the NBTT of Tanzania do appear to be rather persistent.

For Nigeria the median-unbiased estimate of $\alpha$ is 1.00 , as opposed to the least squares estimate of 0.913 . The length of the 90 percent confidence interval for the median-unbiased estimate of $\alpha(0.929,1.00)$ indicates that $\alpha$ is estimated quite precisely. Also, the IRF for the MU estimate do not decline monotonically toward zero. The estimates yield an infinite [LS $11.494, \mathrm{MU} \infty$ ] increase in the estimate of CIR (the total cumulative effect of a unit shock on the future evolution of the price series). This indicates that, for example, a unit shock to the NBTT of Nigeria generates an eventual $(t=\infty)$ infinite displacement of the level of the NBTT - the effect of a unit shock becomes a permanent component of the time series. Moreover, the time it takes for half of the impulse response of a shock to Nigeria's NBTT to dissipate is 7.615 years for the LS estimate, while the MU estimate indicates that NBTT shocks do not dissipate. Accordingly, shocks to the NBTT of Nigeria are permanent, and so it does not display mean-reverting behavior in response to a shock. The MU estimates of HLS and the associated confidence intervals indicate that there is much better evidence in favor of very long-lived shocks for Nigeria's NBTT than for shocks to the NBTT of Tanzania. In addition, shocks to the NBTT of Nigeria are significantly longer-lived than those affecting the NBTT of Mozambique. ${ }^{16}$

\section{Structural Breaks}

It is well known that unit root tests have difficulty in distinguishing between nonstationarity and stationarity with a structural break (Perron (1989)). Moreover, autoregressive models with (endogenous or exogenous) structural change impart bias to the

\footnotetext{
${ }^{16}$ The difference between the HLS for any two given countries' NBTT is statistically significant (at the five percent level) if the median-unbiased estimate of the confidence interval for the HLS of the first NBTT series lies outside the confidence interval for the HLS of the second NBTT series. For example, the difference between the median estimates of the HLS of the NBTT for Mozambique (0.960) and for Nigeria ( $\infty)$ is statistically significant, as the 90 percent confidence interval for the HLS of Mozambique (0.450-3.009) does not overlap with the confidence interval for the HLS of Nigeria $(9.422-\infty)$.
} 
autoregressive coefficient and diminish the power of standard unit root tests. Our analysis of the persistence of shocks has been predicated on the absence of structural breaks which might impart persistence to the evolution of the NBTT series. For the finitely-persistent NBTT series ( 28 of the 42 series analyzed in this paper), McDermott (1994) has shown that the median-unbiased persistence measure is invariant to the presence of a break. However, for the NBTT series subject to permanent shocks (14 of the 42 series), not accounting for structural breaks may matter, as for these series we may have erroneously rejected a finding of finite persistence (with a break) in favor of a finding of permanent shocks. Accordingly, we implement the Zivot-Andrews (1992) test for structural breaks for the NBTT series subject to permanent shocks, and evidence of a significant structural break is found for three of these series (Ghana, Rwanda and Togo). ${ }^{17}$ Using the methodology suggested by McDermott (1994), the median-unbiased estimates of $\alpha$ for these three countries were then corrected to take account of this structural break. ${ }^{18}$

\section{Interpreting the Persistence Results}

In interpreting the results set out in Appendix II it should also be kept in mind that the actual HLS for any given shock to the NBTT has a 50 percent chance of being lower than the estimated median HLS, and a 50 percent chance of exceeding the estimated median HLS. For example, we can examine the two contrasting cases of Gambia and Zambia. While the estimated median HLS for Zambia is 7.7 years (Table 3, Figure 2 and Appendix II), half of the actual realizations of the HLS for Zambia's NBTT will be less than, and half will exceed, the estimated median HLS. While there is not much scope for altering domestic savings to smooth national consumption for the long-lived shocks to the NBTT of Zambia, in contrast, there is much greater scope to do so for the relatively short-lived shocks to the NBTT of Gambia, given that the estimated median HLS to Gambia's NBTT is only 1.4 years.

${ }^{17}$ The Zivot-Andrews (1992) sequential unit root test, allowing for a regime change (level and trend shift) at an unknown (endogenous) breakpoint, has a critical value (at the five percent level of significance) of -5.08 . Calculated test statistics smaller (more negative) than this critical value indicate rejection of the null hypothesis of a unit root-the test statistics and date of the break were: Ghana $(-5.42,1976)$, Rwanda $(-5.14,1975)$ and Togo $(-7.14,1973)$.

${ }^{18}$ By undertaking the correction, we can measure the extent to which not accounting for a structural break has biased the estimate of the autoregressive parameter $(\alpha)$ toward one. Using the results provided in McDermott (1994, Table 3.1), after correcting for the structural break the asymptotically median-unbiased estimate of $\alpha=0.651$ for Ghana, with a 90 percent confidence interval of $(0.491,0.765)$. This corrected measure of $\alpha$ for Ghana has been used in the calculations contained in Table 3, Figure 2 and Appendix II. The original (uncorrected) median-unbiased estimate for Ghana was $\alpha=1.00$, with a 90 percent confidence interval of $(0.814,1.000)$. Similar corrections have been implemented to derive asymptotically medianunbiased estimates of $\alpha$ for Rwanda (median $0.592,90$ percent confidence interval $(0.429$, $0.715)$ ) and Togo (median $0.570,90$ percent confidence interval $(0.407,0.696)$ ) 
Table 3. Persistence of Shocks to the Net Barter Terms of Trade, Sub-Saharan Africa, 1960-96

\begin{tabular}{|l|l|l|l|l|}
\hline HLS less than 2 years & \multicolumn{1}{|c|}{ HLS 2-4 years } & HLS 4-6 years & HLS 6-30 years & \multicolumn{1}{|c|}{ HLS $\infty$} \\
\hline Benin & Burkina Faso & Guinea & Congo, Dem. Rep. & Angola \\
Burundi & Central African Republic & Madagascar & Liberia & Botswana \\
Comoros & Chad & Senegal & Sudan & Cameroon \\
Equatorial Guinea & Ethiopia & & Tanzania & Congo \\
Gambia & Mauritius & & & Côte d'Ivoire \\
Ghana & Nigcr & & & Gabon \\
Guinea-Bissau & Sierra Leone & & & Kenya \\
Malawi & & & & Mauritania \\
Mali & & & & Nigeria \\
Mozambiquc & & & & Ugandh Africa \\
Rwanda & & & & \\
São Tomé and Principe & & & & \\
Seychelles & & & & \\
Somalia & & & & \\
Togo & & & & \\
Zimbabwe & & & & \\
\hline
\end{tabular}

Source: Authors' calculations, derived using equation (4) and the median-unbiased estimates of the autoregressive parameter $(\alpha)$ set out in Appendix II.

Notes: HLS (half-life of shock) is the length of time until the impulse response of a unit shock to an economic time series is half its initial magnitude.

Table 4. Persistence of Shocks to the Income Terms of Trade, Sub-Saharan Africa, 1966-96

\begin{tabular}{|l|l|l|l|l|}
\hline HLS less than 2 years & \multicolumn{1}{|c|}{ HLS 2-4 years } & HLS 4-6 years & HLS 6-30 years & \multicolumn{1}{|c|}{ HLS $\propto$} \\
\hline Benin & Cameroon & Rwanda & Congo & Congo, Dem. Rep. \\
Burkina Faso & Côte d'Ivoire & Swaziland & Somalia & Gabon \\
Contral African Republic & Lesotho & & & Kenya \\
Chad & Máli & & & Madagascar \\
Gambia & Sicrra Leone & & & Mauritius \\
Malawi & South Africa & & & Nigeria \\
Mauritania & Sudan & & & \\
Niger & & & & \\
Senegal & & & & \\
Togo & & & & \\
Zambia & & & & \\
\hline
\end{tabular}

Source: Authors' calculations, derived using equation (4).

Notes: HLS (half-life of shock) is the length of time until the impulse response of a unit shock to an economic time scries is half its initial magnitude. 
The above results indicate that, using the median-unbiased model, the majority (31) of the 42 countries are subject to NBTT shocks which are finitely-persistent, while 11 countries experience permanent shocks to their NBTT series. We find that the persistence of shocks to the NBTT (as measured by the HLS) is less than four years for 23 of the 42 countries. These countries have substantial scope to smooth national consumption by increasing domestic savings in response to temporary positive shocks. The potential benefits of informed savings responses are greatest for those countries with persistence of shocks lasting less than two years, that is for 16 of the 42 countries (Table 3 and Figure 2).

Again taking the examples of Mozambique and Tanzania, respectively, and using the HLS as our measure of persistence, we find that the estimated 90 percent confidence intervals range from 0.450 to 3.009 years and from 1.956 years to infinity (Appendix II). Accordingly, 5 percent of the actual realizations of the HLS for the NBTT of Mozambique will exceed 3.009 years, while 5 percent (or more) of the actual realizations of the HLS for the NBTT of Tanzania will be permanent. This implies that in the presence of a positive shock to the NBTT it is likely to be much more important for Mozambique to increase domestic saving to smooth the path of national consumption than Tanzania, as the former has a much greater chance of experiencing short-lived shocks than the latter.

Consider the 11 countries which have NBTT shocks which are typically very longlived (permanent). For these countries, while 5 percent of the shocks to their NBTT will be shorter in duration than the lower bound of the 90 percent confidence interval and half of the shocks to the NBTT will be finite, half of the shocks to their NBTT will be permanent. These results indicate that external financing as a response to adverse NBTT shocks was not a sensible strategy for those countries, as there was a much greater likelihood that such borrowing would confront shocks which lasted for a long time, and thus may not have been financially sustainable.

Finally, we carried out several checks of the robustness of the above persistence calculations. First, we examined in greater detail the persistence of shocks to the prices of Uganda's major commodity exports and imports. We found that the persistence of shocks to the prices of individual Ugandan commodities is very similar to that found in previous work which examined the persistence of shocks to world commodity prices (see Cashin, Liang and McDermott (1999) and Appendix III). Second, we examined the persistence of shocks to the NBTT using terms of trade data drawn from two alternative sources-the World Bank's African Development Indicators (ADI) and the International Monetary Fund's International Financial Statistics (IFS). For those countries in both the World Bank's WDI and ADI databases, and in both the World Bank's WDI and International Monetary Fund's IFS databases, there were no cases where there was a statistically significant difference in the measured persistence of shocks to the NBTT (see Appendix IV). 


\section{Size of Shocks to the Net Barter Terms of Trade}

While it is important to ascertain the duration of shocks to commodity prices, knowledge of the size of NBTT shocks is also of great interest. Very small, yet long-lived, shocks will have different implications for the appropriateness of any policy response than very large, long-lived shocks. In this connection, our estimation of persistence enables a calculation of the size of shocks to the NBTT, using the standard error of the regression (equation (1)). The values for the standard error of the regression for each country are displayed in Figure 3. As an example, in the case of Côte d'Ivoire, the standard error of the regression is 0.093 , indicating that one-third of the time, the NBTT of Cote d'Ivoire will be faced with the prospect of a change of greater than 9 percent. Accordingly, in any given year there is a one-in-six chance that the realized NBTT of Côte d'Ivoire would fall (or rise) by about 9 percent or more. In contrast, for the Congo the standard error of the regression is 0.221 , indicating that one-third of the time, the NBTT of the Congo will be faced with the prospect of a change of greater than 22 percent. Accordingly, in any given year there is a onein-six chance that the realized NBTT of the Congo would fall (or rise) by about 22 percent or more. Clearly, not only are NBTT shocks often long-lived, but they can also be large in magnitude.

We also examined whether there was a significant relationship between the persistence of shocks to the NBTT (as measured by the HLS) and the size of NBTT shocks (as measured by the standard error (SE) of the regression (equation (1)), using Spearman's rank correlation coefficient. Even given varying speeds of mean reversion following a shock to the NBTT, countries which typically experience relatively large shocks to the NBTT may have longerlived shocks than those which typically experience relatively small shocks. However, we find that the persistence and size of shocks to the NBTT are only weakly correlated the null hypothesis that the persistence of shocks to the NBTT is not rank correlated with the size of shocks to the NBTT can only be rejected at the 25 percent level of significance. ${ }^{19}$

\section{Persistence of Shocks to the Income Terms of Trade}

We would expect, a priori, that shocks to the volume of exports produced by the commodity-exporting countries of Sub-Saharan Africa would most likely be transitory, reflecting the short-lived (positive and negative) effects of weather and other natural influences on the level of production and export. Accordingly, we expected to observe the persistence of shocks to the income terms of trade (YTT) being of shorter duration than the

\footnotetext{
${ }^{19}$ The rank correlation coefficient (which is the correlation coefficient between the ranked values of HLS and SE) is 0.123 , while the critical value (given $N=42$ countries) at the 25 percent level of significance (for a one-tailed test) is 0.107 ( $\operatorname{Zar}$ (1972)).
} 
Figure 3. Size of Shocks to the Net Barter Terms of Trade, Sub-Saharan Africa, 1960-96

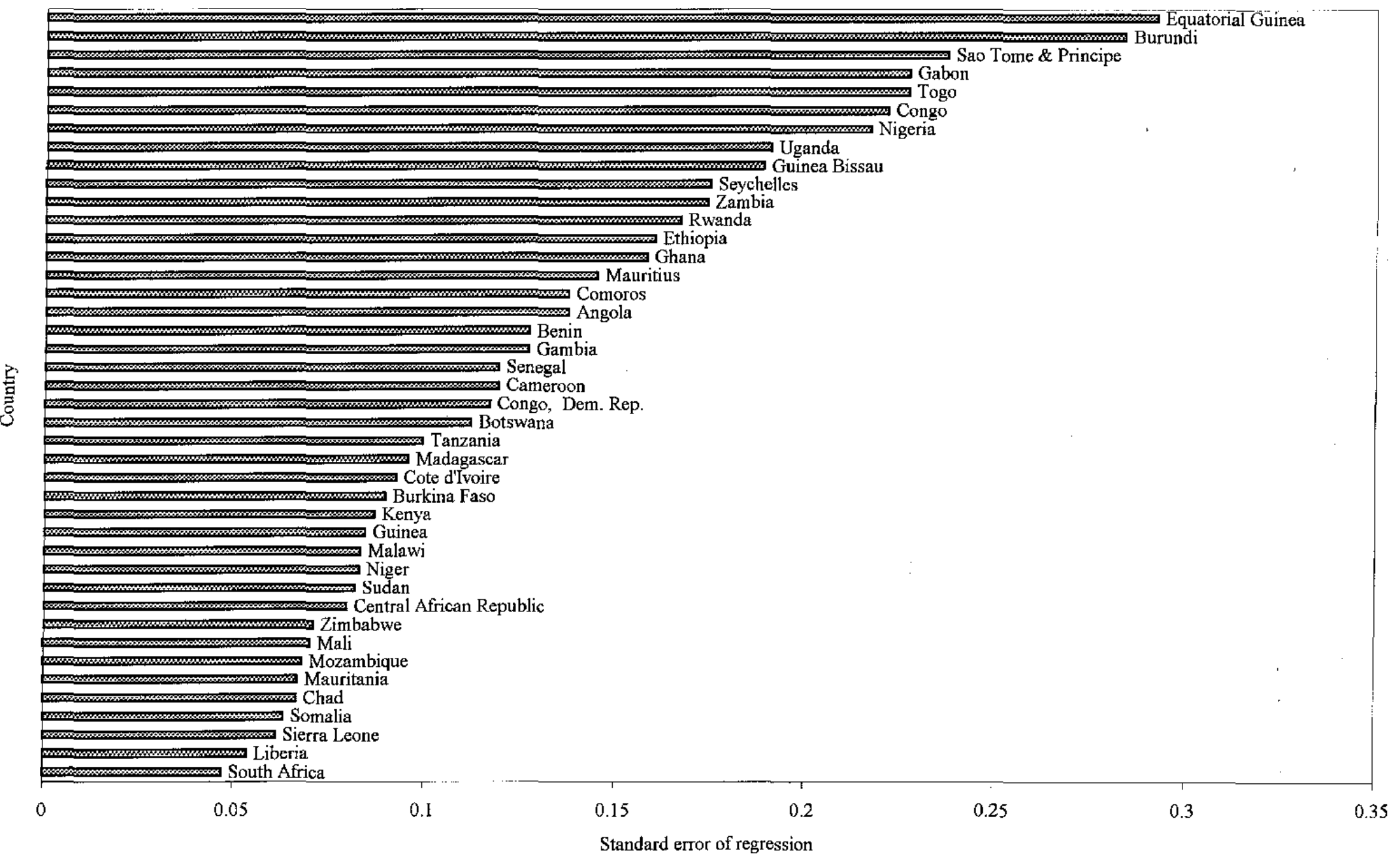

Source: Authors' calculations.

Note: Size of terms of trade shock is derived from the standard error of the regression (equation (1)) used to calculated the average duration of shocks. 
persistence of shocks to the NBTT. ${ }^{20}$ However, our results for the YTT do not reflect such a differentiation from the results for the NBTT (Table 4). The pattern of bifurcation observed for the NBTT is repeated for the YTT, with 19 of the 29 countries experiencing HLS to their YTT of less than four years, while seven of the 29 countries experience permanent shocks to their YTT.

For the 27 countries with observations for both the NBTT and YTT series, in 16 countries the persistence of shocks to the YTT is lower than the persistence of shocks to the NBTT, yet for none of these countries is the difference in HLS statistically significant (as the 90 percent confidence interval of the HLS to the NBTT does not contain the 90 percent confidence interval of the HLS to the YTT) ${ }^{21}$ Similarly, in the seven countries where the persistence of shocks to the YTT is greater than the persistence of shocks to the NBTT, in none of these countries is the difference in HLS across both measures of the terms of trade statistically significant. In addition, using a one-tailed test, the persistence of shocks to the NBTT and YTT are rank correlated at the 15 percent level of significance. For the 27 countries the correlation of the ranked autoregressive parameters is 0.247 , while the critical value at the 10 percent level of significance is 0.255 (Zar (1972)). Although the results for the YTT are of interest, in the remainder of the paper we will concentrate on analyzing the determinants of the heterogeneity in the persistence of shocks to the NBTT.

\section{E. Policy Implications}

Why are estimates of the duration of terms of trade shocks useful for policy-makers in Africa? Firstly, the extent to which a country fundamentally adjusts to a shock, versus attempts to smooth the economic effects through international borrowing or domestic savings, should depend on whether shocks to the terms of trade are typically short-lived or longlasting. The decision regarding borrowing or adjusting to negative shocks was important for African countries during the 1960s, 1970s and early-1980s, while since the debt crisis of the

${ }^{20}$ The 29 sub-Saharan African countries in the sample for our YTT analysis are those listed in Appendix II, excepting Angola, Botswana, Burundi, Comoros, Equatorial Guinea, Ethiopia, Guinea, Guinea-Bissau, Liberia, Mozambique, São Tomé and Principe, Seychelles, Tanzania, Uganda and Zimbabwe, which were deleted due to a lack (or absence) of YTT data, while Swaziland and Lesotho were included (having been excluded from the NBTT data). The data for all countries run from 1966-96, excepting: Mali (1967-96); Niger (1966-90); and Sudan (1966-91). The data are expressed in logarithmic form.

${ }^{21}$ For four countries, the estimated HLS to the YTT and NBTT were both permanent (Nigeria, Kenya, Ghana and Gabon). In addition, for those countries with permanent shocks to their YTT (Democratic Republic of Congo, Gabon, Ghana, Kenya, Madagascar, Mauritius and Nigeria), none had significant structural breaks according to the Zivot-Andrews (1992) test for endogenous breaks. The results for the median-unbiased estimates of the autoregressive parameter of equation (1) using the YTT data are not presented in this paper, but are available from the authors on request. 
mid-1980s African countries have typically not had access to world capital markets. Indeed, uncertainty concerning the longevity of terms of trade shocks may have contributed to overborrowing during this period, which is at the root of the current debt problems of many African countries (Brooks et al. (1998)). Countries with long-lived shocks that were mistakenly perceived as temporary may have been more likely to undertake unsustainable borrowing. ${ }^{22}$

For those countries that borrowed externally prior to the mid-1980s in an attempt to smooth shocks, the relatively long-lived nature of terms of trade shocks would indicate greater potential for encountering debt-servicing difficulties. It is interesting to note that 84 percent (16 out of 19) of the countries which typically have long-lived shocks to their NBTT (HLS greater than four years) are designated as HIPCs (Heavily Indebted Poor Countries), while a slightly lower fraction, 74 percent (17 out of 23) of countries which typically have short-lived shocks to their NBTT are also HIPCs. ${ }^{23}$ The high proportion in both groups reflects the large share of all SSA countries (approximately 70 percent) that are HIPCs. Although the countries with relatively short-lived shocks should have been somewhat better placed to successfully engage in external borrowing and lending to smooth consumption, a number have still developed large and unsustainable debt burdens. Clearly there are many other factors, most importantly the appropriateness of policy responses, that have influenced how well countries have managed terms of trade shocks and external debt.

African policy-makers make important decisions that influence domestic savings rates in response to positive terms of trade shocks. Estimates of the expected duration of a positive temporary shock, however formed, are the basis for public and private decisions on savings rates out of temporarily higher income. Following from the consumption-smoothing effect in intertemporally-optimizing models, the shorter the expected period of the shock the higher

\footnotetext{
${ }^{22}$ For example, Senhadji (1997) shows that overborrowing will occur if a permanent decline in the terms of trade is perceived to be transitory, or if a transitory improvement is believed to be permanent. In his model, uncertainty about shock duration generates autocorrelated forecast errors that can lead to substantial debt accumulation.

${ }^{23}$ This analysis is based on the original group of 41 HIPCs, 33 of which are in SSA. Following the Cologne Summit of June 1999, the Initiative has been enhanced so that a potentially broader set of countries could qualify for assistance.
} 
should be the windfall savings rate. Measures of persistence and their associated confidence intervals could be useful in informing savings decisions. ${ }^{24,25}$

Secondly, estimates of the typical duration of terms of trade shocks could be a useful vulnerability indicator when conducting debt sustainability analyses. Countries are eligible for assistance under the IMF-World Bank HIPC Initiative if the net present value of debt-toexports and the debt-service ratio are above certain ranges judged as unsustainable. Assistance is geared to reduce these ratios to country-specific targets, determined by a vulnerability analysis that considers indicators such as the export concentration and the variability of exports. The idea is that the more concentrated are a country's exports in a few main commodities, and the more variable are export revenues, the more uncertain are the export projections and the greater the likelihood that a country may experience difficulty in servicing a given amount of debt. The typical duration of shocks to a country's terms of trade, and the variability of median estimates of these shocks, is another important indicator of the uncertainty attached to export projections. If shocks to the export price index or terms of trade are typically quite long-lived, then such a country may be more vulnerable to encountering protracted and escalating debt-service problems.

\section{EXPlaining the Persistence of Terms of Trade Shocks}

Of particular interest is the bifurcation of the estimated median duration of shocks to the NBTT, with 23 countries experiencing HLS of less than four years, only eight countries experiencing shocks to their NBTT of between 4-30 years, and 11 countries experiencing permanent shocks to their NBTT. We now turn to analyze what might account for this pattern in the persistence of shocks to the NBTT.

${ }^{24}$ While the results in this paper do not provide information on the differential (if any) between the persistence of positive and negative shocks to the NBTT, there is some evidence on the duration and amplitude of positive shocks (booms) and negative shocks (slumps) in world commodity prices. Cashin, McDermott and Scott (1999) find that for the majority of world commodity prices, the duration of price slumps typically exceeds the duration of price booms, yet the amplitude of price movements during booms and slumps are quite similar.

${ }^{25}$ In a 23-country comparative study of temporary trade shocks, Collier and Gunning (1999) find that private savings rates out of positive shocks were quite high, consistent with agents perceiving shocks as having a substantial temporary component. Aggregate savings was lower and more varied only in cases where the shock income was received indirectly, that is where the windfall was initially received by either the public or the private sector and transferred to the other sector. Collier and Gunning argue that this poorer savings response reflects the loss of information which occurs when windfalls are transferred. This points again to the usefulness of clear information on the likely duration of terms of trade shocks. 


\section{A. Time-Series Analysis of Persistence}

As part of our effort to understand what drives differences in the persistence of shocks to the NBTT across African countries, we considered the time series properties of the two series from which the NBTT index is constituted - the indices of export and import unit values. In Section IV we found that all but 11 of the 42 NBTT series exhibited finitelypersistent shocks. Note that as argued by Powell (1991) in the context of his analysis of the commodity terms of trade, a stationary terms of trade series implies a cointegrating relationship between export prices and import prices.

Of the 42 countries for which we have data on their NBTT, the export and import unit value indices used to construct the NBTT series were available for 32 of these countries. ${ }^{26}$ For these 32 countries we typically find that both the numerator (unit price of exports) and denominator (unit price of imports) are nonstationary series. ${ }^{27}$ Asymptotically, we would then expect that:

(i) If the numerator and denominator are both $\mathrm{I}(1)$ series and are cointegrated, then (given cotrending (drift of similar sign in the two series) or no drift) the ratio (NBTT) should exhibit finitely-persistent shocks. Using the Phillips-Ouliaris (1990) cointegration test, for the cointegrating regression of the export price index on the import price index and a constant term, we find that for those countries which exhibit finitely-persistent shocks (and have nonstationary price indices), for only six of the 23 countries is there cointegration between the two price series (Benin, Central African Republic, Liberia, Mali, Niger and Somalia, see Appendix V). Moreover, the cointegrating parameter (the value of the parameter on the import price index in the cointegrating regression) does not differ significantly from unity for only two of the six countries (Central African Republic and Mali). For these same two

${ }^{26}$ The export and import unit value indices were obtained from the World Bank, and were obtained from the same UNCTAD database used to derive the NBTT series (see the description and derivation of that data in Section IV). All data are expressed in logarithmic form. The unit value indices were available for the period 1960-96, for all the countries listed in Appendix II, excepting: Botswana, Burundi, Comoros, Equatorial Guinea, Guinea, GuineaBissau, São Tomé and Principe, Seychelles, South Africa, and Zimbabwe.

${ }^{27}$ The results of the Phillips-Perron (1988) unit root tests (with a constant term) for the import and export unit value series are available from the authors on request. The results of the Phillips-Ouliaris (1990) cointegration tests (with a constant term) are presented in Appendix V. Both tests were computed using the Fejer kernel and the automatic bandwidth selector of Andrews (1991). 
countries, the logarithm of the ratio of export to import prices is a stationary series. ${ }^{28}$ Importantly, apart from six cases (Burkina Faso, Chad, Madagascar, Malawi, Mauritius and Mozambique), in 11 of the remaining 17 countries there is evidence of significant parameter instability in the cointegrating relationship between the two price series, as the null hypothesis of stable parameters in the Hansen (1992) stability tests is rejected. This instability may explain our inability to find a long-run relationship between the nonstationary export and import price series of countries with finitely-persistent shocks to their NBTT. As with Powell (1991), we would conjecture that the excess kurtosis clearly present in commodity prices (Deaton and Laroque (1992), Cashin, Liang and McDermott (1999)) feeds into the often sharp changes observed in the indices of export prices and import prices, yielding excess kurtosis in the export and import price series of commodity-exporting developing countries, and instability in the measured cointegrating relationship between the two price series. ${ }^{29}$

(ii) If the numerator and denominator are both $\mathrm{I}(1)$ series and yet not cointegrated, then shocks to the ratio (NBTT) should be permanent; the absence of cointegration could be due to divergent trends in the two series. We find that, as expected, for those seven countries which exhibit permanent shocks and have nonstationary price indices (Angola, Cameroon, Congo, Gabon, Mauritania, Nigeria and Uganda), for none of them is there cointegration between the two price series. In addition, for none of these seven countries is the logarithm of the ratio of export to import prices a stationary series (Appendix V).

(iii) If the numerator is $\mathrm{I}(0)$ and the denominator is $\mathrm{I}(1)$, or vice versa, then shocks to the ratio (NBTT) should be permanent. However, it may be the case that shocks to the NBTT are found to be finitely-persistent, which is not theoretically possible. This could occur if the jump (or typical movement) in export (or import) prices is greater than the trend movement in import (or export) prices, which would imply that the jump accounts for the bulk of the variance in the series. The NBTT plotted in Figure 1 reveal that trends in the NBTT are relatively small when compared with fluctuations in the NBTT. In short, with finite data the variance of export and import prices can dominate the trend (drift) in each series. This makes the notion of examining the properties of any given country's export and import price series,

\footnotetext{
${ }^{28}$ Phillips-Perron (1988) unit root tests (with a constant term) were carried out on the logarithm of the ratio of export to import prices - which forces the cointegrating parameter to equal unity. The null was able to be rejected for only five of the 32 countries, indicating that the difference between the indices of export and import prices is stationary for these countries. ${ }^{29}$ Changes in (the logarithm of the first difference of) export and import prices for SSA countries typically have distributions with fat tails. For the 32 countries, 23 of the import price series exhibit excess kurtosis, while only 18 of the export price series do so.
} 
in an attempt to understand the factors influencing the persistence of shocks to the NBTT, a dicey affair. ${ }^{30}$

\section{B. Cross-Sectional Analysis of Persistence}

A second direction to explore is whether the heterogeneity in the distribution of the persistence of shocks to the NBTT can be explained by country-specific characteristics. This approach is related to some recent papers in the purchasing power parity (PPP) literature, which have attempted to isolate the empirical determinants of the rate of reversion to PPP. These authors have focused on different types of explanations for the slow speed of reversion, including market microstructure features such as the extent of competition, market size and geographic factors, and macroeconomic determinants (see Cheung et al. (1999)).

In our case, however, previous work provides little or no guidance in choosing country-specific factors that may be important determinants of the differences in persistence of shocks to the NBTT across developing countries. However, there is some evidence that changes in a developing country's NBTT are typically driven by changes in the world price of its dominant primary commodity exports (Bidarkota and Crucini (1997)). Accordingly, one testable hypothesis is that the persistence of shocks to a country's NBTT should be related to the persistence of shocks to the price of that country's main exportable commodity. For example, Table 3 shows that all the oil-exporting countries (except Equatorial Guinea) experience permanent NBTT shocks, consistent with the findings of Cashin, Liang and McDermott (1999) that shocks to the world price of petroleum are permanent. The other factors that we consider relate to the structure of a country's trade, its share in world markets, the demand for its commodities, and structural factors such as its exchange rate regime (see Appendix VI for variable definitions). Our measure of the persistence of shocks to each country's NBTT is the median-unbiased estimate of the autoregressive parameter $\alpha$ of equation (1), denoted as ALPHA, and listed in Appendix II.

\section{Bivariate Correlation Analysis}

Bivariate correlation analysis is a straightforward method of summarizing the relationship between our measure of the persistence of shocks to the NBTT and the candidate variables which determine the persistence of such shocks. Figures 4 and 5 show the correlation of each country's measure of the persistence of shocks to its NBTT (ALPHA) with particular variables, beginning with the persistence of shocks to the world price of the

${ }^{30}$ Of those four countries with one of the import or export price series being stationary (Benin, Côte d'Ivoire, Kenya and Liberia), only Benin and Liberia exhibit finitely-persistent shocks to their NBTT (see Table 3). The import and export prices of both Côte d'Ivoire and Kenya exhibit excess kurtosis-the import and export prices of Benin do not, while the export prices of Liberia do not. 
country's main commodity export (ALCOM) ${ }^{31}$ However, it could also be the case that a country has several important exportables, and so we consider whether there is any link between ALPHA and the concentration of a country's exports (as measured by the share of its top 3 commodities in total commodity exports, TOP3). This effect will depend on whether a country is concentrated in commodities that typically have long-lived or short-lived shocks, as discussed below. It may also be that countries with some market power in a commodity will be able to influence the price for longer periods, implying that shocks to their NBTT may be more persistent - this is proxied by the world market share of the country's top 3 commodity exports (BIGX). On the import price side, countries with a larger share of petroleum imports in total imports (OILM) are likely to have longer-lived shocks to their NBTT. For each of these four variables, there is some evidence of a positive relationship with ALPHA (see Figure 4).

We also consider the relationship between the exchange rate regime and the persistence of shocks to the NBTT. Hoffmaister et al. (1998) show that terms of trade shocks had a larger impact on output fluctuations in CFA-countries, interpreting this as reflecting the fixed exchange rate arrangement (which does not buffer these countries from external shocks). ${ }^{32}$ The correlation of ALPHA with a dummy for the CFA countries (DCFA) is positive, while the correlation between a fixed exchange rate dummy (DFIXED) and ALPHA is negative; in neither case was the bivariate relationship statistically significant. This does not provide any evidence that the greater output effect of NBTT shocks for CFA or fixed exchange rate countries is accounted for by more persistent NBTT shocks.

Although the bulk of Africa's exports are primary commodities, there is some variation in the share of commodities in total exports across countries. As mentioned above, Mendoza (1995) also estimates terms of trade shock persistence for a sample of developing countries - he finds that shock persistence is longest for Africa, the region where commodities are the highest share of total exports. Thus, within Africa, we hypothesize that countries with larger shares of commodity exports in total exports (COMSH) are likely to have more persistent NBTT shocks. However, since the longer average shock persistence of Africa is influenced by oil-exporters with very long-lived shocks, Figure 5 also shows the correlation between each country's share of nonfuel commodity exports in total exports (NONFUEL) and the measure of NBTT shock persistence (ALPHA), which is negative.

World demand for a country's exports clearly influences movements in that commodity's price. If business cycles in a country's main trading partners are very long, then

\footnotetext{
${ }^{31}$ The country abbreviations used in Figures 4 and 5 are described in Appendix VII. Candidate explanatory variables are mainly measured as averages during part of the 1960-96 period, as described in Appendix VI.

${ }^{32}$ In a broad sample of developing countries, Berg and Broda (1999) also find that the output effects of terms of trade shocks are larger in countries with pegged exchange rates relative to countries with more flexible arrangements.
} 
Figure 4. Net Barter Terms of Trade Shock Persistence and Country Characteristics ${ }^{\prime \prime}$
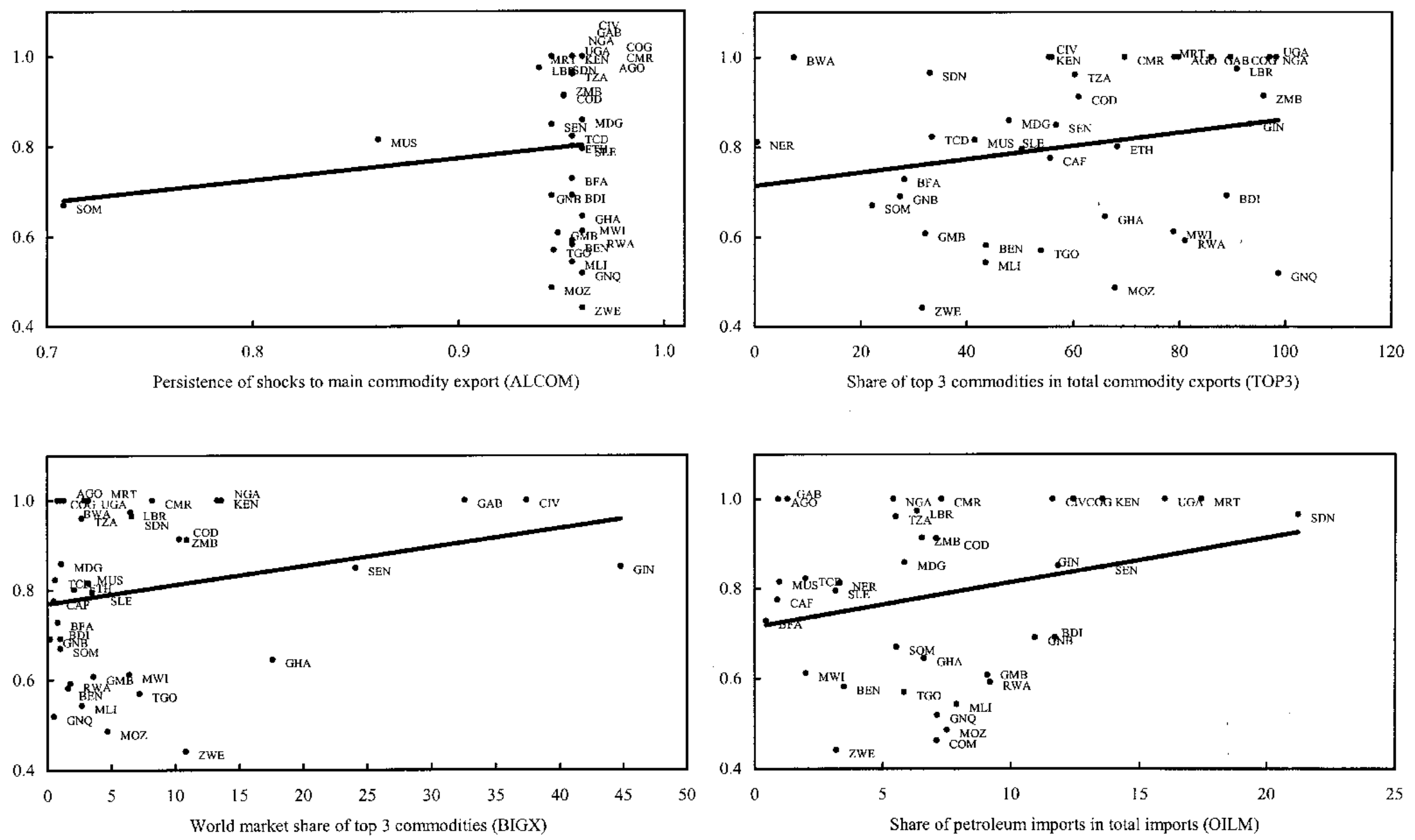

Source: Authors' calculations.

${ }^{1 /} \mathrm{Y}$-axis on all charts represents estimate of NBTT shock persistence (ALPHA).

Notes: See Appendix VI for variable descriptions and definition, and Appendix VII for country abbreviations. 
Figure 5. Net Barter Terms of Trade Shock Persistence and Country Characteristics"
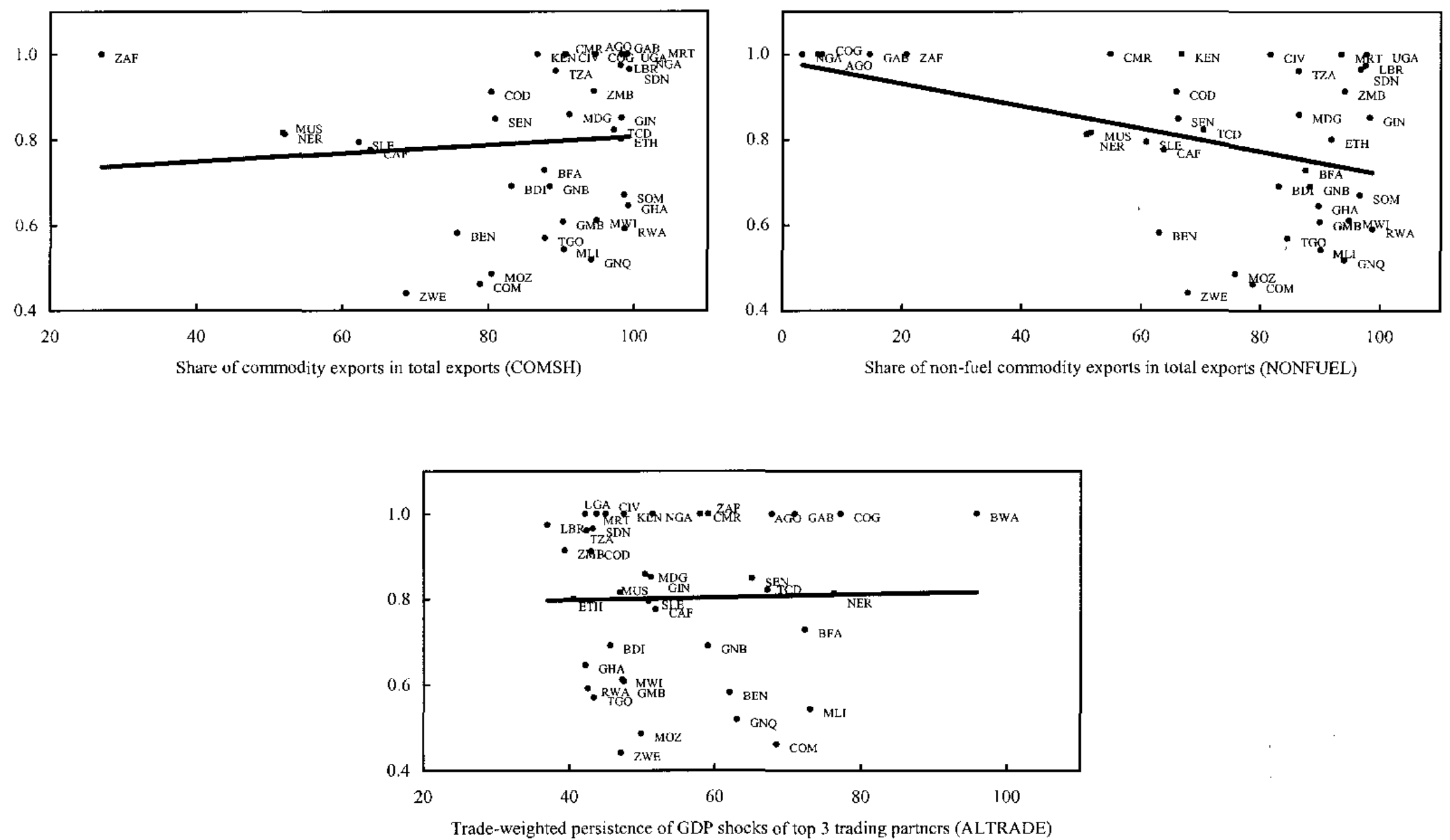

Source: Authors' calculations.

${ }^{\mathrm{l}} \mathrm{Y}$-axis on all charts represents estimate of NBTT shock persistence (ALPHA).

Notes: See Appendix VI for variable descriptions and definition, and Appendix VII for country abbreviations. 
long-lived demand changes are likely to induce long-lived price shocks. For each country, we calculate median-unbiased estimates of the persistence of shocks to the real GDP of its top 3 trading partners (ALTRADE) and combine them into a demand proxy using trade weights. However, the bivariate correlation with ALPHA is only weakly positive (Figure 5). Given our finding in Section V.A of the long-lived persistence of shocks to the import price series of SSA countries, and the dominance of manufactured goods in SSA imports, we examine whether there is any relationship between ALPHA and each country's share of manufacturing imports in total imports (MANM). Following our work in Section IV.C, we also look at whether there is any basis for the hypothesized link between the size of shocks to the NBTT and the duration of such shocks, by considering the average size of terms of trade shocks (SIZE) in the bivariate correlation analysis. Finally, given the longevity of shocks to the price of petroleum, the correlation of ALPHA with a dummy variable for the six oil-exporting SSA countries (DOIL) is also examined.

In summary, of the 12 candidate explanatory variables described above, significant correlations (at the 10 percent level or greater) with ALPHA were found for: share of top 3 commodities in total commodity exports (TOP3); the share of nonfuel commodity exports in total exports (NONFUEL); the share of petroleum imports in total imports (OILM); and the dummy for oil-exporting countries (DOL). ${ }^{33}$

\section{Limited Dependent Variable Analysis}

We explore the cross-country differences in the persistence of shocks to the NBTT more formally by regressing each $i$ th country's estimated autoregressive parameter from the UR/AR regression (ALPHA, derived from estimates of equation (1) and reported in Appendix II), on the abovementioned explanatory variables. Accordingly, the first regression specification is:

$$
A L P H A_{i}=\beta_{0}+\beta_{1} \text { NONFUEL } L_{i}+\beta_{2} \text { TOP }_{i}+\beta_{3} O L L M_{i}+\beta_{4} D O I L_{i}+\eta_{i}
$$

where the explanatory variables are as described above, $\eta_{i}$ is the disturbance term, and $i=1, \ldots N$ where $N=36$. The first three columns of Table 5 show the results explaining NBTT shock persistence (ALPHA) using Tobit models, which are appropriate given that the

\footnotetext{
${ }^{33}$ The 10 percent critical value is calculated as $1.65 / N^{1 / 2}$, where $N$ is the number of countries. As data availability varies across countries, $N=27$ countries had data for all 12 variables in the bivariate correlation analysis, which gives a critical value of 0.32 . The bivariate correlation with ALPHA of each of the following variables is: DOIL (0.44); NONFUEL (-0.37); OILM (0.35); TOP3 (0.34); BIGX (0.28); COMSH (0.28); DFIXED (-0.23); SIZE (0.13); DCFA (0.10); MANM (-0.06); ALCOM (0.06); and ALTRADE (0.05).
} 
Table 5. Explaining the Persistence of Shocks to African Countries' Net Barter Terms of Trade

\begin{tabular}{|c|c|c|c|c|c|c|c|c|c|c|}
\hline \multirow[b]{3}{*}{ Variable } & \multicolumn{6}{|c|}{ Tobil Models } & \multirow{2}{*}{\multicolumn{2}{|c|}{$\begin{array}{l}\text { OLS } \\
(4) \\
\end{array}$}} & \multirow{2}{*}{\multicolumn{2}{|c|}{$\begin{array}{c}\text { Probit } \\
(5) \\
\end{array}$}} \\
\hline & \multicolumn{2}{|c|}{$(1)$} & \multicolumn{2}{|c|}{$(2)$} & \multicolumn{2}{|c|}{$(3)$} & & & & \\
\hline & Coeff & t-stat & Coeff & t-stat & Coeff & t-stat & Coeff & t-stat & Coeff & z-stat \\
\hline Constant & 1.033 & 7.00 & 1.4928 & 2.00 & 1.0191 & 6.03 & 0.8352 & 6.95 & -0.2770 & -0.58 \\
\hline Share of nonfuel commodity exports & -0.0067 & -3.26 & -0.0068 & -3.34 & -0.0066 & -3.32 & -0.0032 & -2.89 & -0.0111 & -2.07 \\
\hline Share of top 3 commodities & 0.0023 & 1.62 & 0.0028 & 1.78 & & & & & & \\
\hline Share of petroleum imports & 0.0223 & 3.17 & 0.0236 & 3.07 & 0.0229 & 2.99 & 0.0149 & 2.50 & 0.0425 & 1.90 \\
\hline Dummy for oil exporters & -0.0109 & -0.08 & & & & & & & & \\
\hline Persistence of main commodity & & & -0.4984 & -0.66 & & & & & & \\
\hline $\begin{array}{l}\text { Main commodity persistence*share } \\
\text { of top } 3\end{array}$ & & & & & 0.0024 & 1.62 & 0.0013 & 1.06 & 0.0099 & 2.02 \\
\hline Log-likelihood & 4.93 & & 2.72 & & 2.45 & & & & -13.97 & \\
\hline$\chi^{2}$ & 23.86 & $(\mathrm{df}=4)$ & $22.60^{*}$ & $(d f=4)$ & $22.05^{*}$ & $(d f=3)$ & & & $15.32^{*}$ & $(\mathrm{df}=3)$ \\
\hline$N$ & 36 & & 33 & & 33 & & 33 & & 33 & \\
\hline $\mathrm{R}^{2}$ & & & & & & & 0.35 & & & \\
\hline
\end{tabular}

Source: Authors' calculations.

Notes: The cross-country regressions listed in columns (1-5) all have ALPHA as the dependent variable, where ALPHA is the median-unbiased estimate of the persistence of shocks to the NBTT, as measured by the regressions of equation (1) and listed in Appendix II. The explanatory variables are: the share of nonfuel commodity exports in total exports (NONFUEL); the share of the country's top 3 commodity exports in total commodity exports (TOP3); the share of petroleum imports in total imports (OILM); a dummy for oil exporters (DOL); the persistence of the country's main commodity export (ALCOM); and an interaction term describing the persistence of commodity price shocks for important commodity exports (formed as ALCOM*TOP3). For variable definitions and derivation, see Appendix VI. "Coeff" denotes the coefficient estimates; " $t$-stat" and " $z$-stat" denote the $\mathrm{t}$-statistics and z-statistics, respectively, for examining whether the coefficient is significantly different from zero; Log-likelihood is the value of the $\log$-likelihood function; $\chi^{2}$ denotes the test of the joint significance of the explanatory variables, with degrees of freedom (df) - an asterisk denotes that the null hypothesis that the coefficients are jointly insignificant is rejected at the 1 percent level; $N$ is the number of countries; and $\mathrm{R}^{2}$ is the coefficient of detcrmination. 
dependent variable is truncated at $1 .^{34}$ In the first regression we include the four variables that were found to have significant bivariate correlations with ALPHA, as shown in equation (5). Column 1 shows that countries with more concentrated exportable commodities (TOP3), and those with larger shares of petroleum imports (OILM) tend to have more persistent NBTT shocks. Countries with large shares of nonfuel exports (NONFUEL) tend to have shorter NBTT shocks. This accords well with the Cashin, Liang and McDermott (1999) finding that the prices of agricultural commodities tend to have shorter shock persistence than the prices of minerals or fuels. The dummy for oil-exporting countries (DOIL) is not significant, and so is dropped from subsequent regressions. In column 2 we add the persistence of shocks to the country's main exportable commodity (ALCOM) to a specification with the three significant variables. Contrary to our hypothesis that the persistence of shocks to the main commodity is likely to be an important determinant of NBTT shock persistence, we find that it is not significant. ${ }^{35}$ However, it may be that the main exportable's shock persistence matters most when a country's exports are very heavily concentrated in that commodity. The expected sign of the commodity export concentration variable would also seem to depend on whether the country's exports are concentrated in commodities which tend to have long-lived or shortlived shocks. This suggests interacting the measures of the persistence of shocks to the price of each country's main exportable (ALCOM) and its measure of commodity export concentration (TOP3). ${ }^{36}$

Column 3 is our preferred specification, which includes as explanatory variables the abovementioned interaction term, the share of nonfuel commodity exports and the share of petroleum imports. The coefficients and t-statistics for the latter two variables remain broadly similar across the different models. The sign on the interaction term is positive, although it is not quite significant at the 10 percent level. Importantly, these three variables retain their sign and significance when any of the other ten candidate variables are added to the model, which are generally insignificant. Our results indicate that a country with a large share of nonfuel commodity exports in total exports tends to have less persistent NBTT shocks. To the extent that these exports are agricultural commodities, this may reflect the key role of weather in the generation of short-lived supply shocks to the prices of commodities. On the import price side, larger shares of petroleum imports in total imports are associated with longer-lived NBTT shocks, consistent with earlier work that found that petroleum price shocks are

\footnotetext{
${ }^{34} \mathrm{Six}$ of the countries included in our sample of 42 SSA countries had to be deleted from the first cross-section regression (column (1)), due to a lack of data on one or more of the explanatory variables. The countries included are those listed in Appendix VII, excepting: Botswana, Comoros, Ethiopia, São Tomé and Principe, Seychelles and South Africa. For similar reasons, three additional countries are excluded from the specifications reported in columns (2)-(5): Central African Republic, Guinea and Niger.

${ }^{35}$ While Mauritius and Somalia appear to be outliers in the relationship between ALPHA and ALCOM (Figure 4), excluding them from the cross-sectional regressions had little effect on the results presented in column 2 of Table 5 .

${ }^{36}$ The bivariate correlation with ALPHA of the interaction term (ALCOM*TOP3) is 0.34.
} 
typically long-lived. Finally, when shocks to the price of a country's main exportable are quite persistent and that commodity accounts for a large share of its total commodity exports, the persistence of shocks to its NBTT is also longer.

The results are similar when estimated using ordinary least squares (column 4), although the interaction term loses significance. The Tobit results are also confirmed using a probit model, where the dependent variable (ALPHA) is transformed into a dummy equal to one for countries with permanent NBTT shocks, and zero for all countries with finitelypersistent shocks (column 5). This provides an indication that the effect of these variables on whether NBTT shocks are permanent or finite is similar to their effect on the degree of persistence for finitely-persistent shocks.

\section{Conclusion}

This paper conducts an empirical analysis of the persistence of shocks to the terms of trade of developing countries; using data on the net barter terms of trade of commodityexporting countries of Sub-Saharan Africa. Previous work on the terms of trade has examined trends and volatility in the commodity terms of trade (the price of primary commodities relative to manufactured goods), while analysis of the properties of countries' actual terms of trade has been neglected. We find that there is little evidence of a stable, long-run relationship between the commodity terms of trade and each country's net barter terms of trade, and so the practice of proxying for movements in any given country's terms of trade by using an aggregate index of the commodity terms of trade is likely to be misleading.

In comparison with results from standard unit root regressions, which are largely uninformative on the question of the persistence of shocks, the scalar persistence measures used in this paper allow for a determination of the typical duration of terms of trade shocks, as well as the variability of this duration. Using annual data on the net barter terms of trade for 42 Sub-Saharan African countries over the period 1960-96, this study finds that there is a bifurcation in the persistence of terms of trade shocks. For about half the countries such shocks are short-lived (where it typically takes less than four years for half of the effect of the initial shock to dissipate), while for one-third of the countries such shocks are typically permanent.

We find that most countries exhibit finitely-persistent terms of trade shocks, which implies that there is a long-run relationship between export and import prices. However, econometric tests were only able to confirm this relationship for some countries, as for many countries there is evidence of instability in the relationship between their export and import prices, which could account for the difficulty in establishing cointegration. In explaining the determinants of the observed cross-country heterogeneity in the typical duration of terms of trade shocks, we find that terms of trade shocks tend to last longer for countries with large shares of petroleum imports in total imports, with small shares of nonfuel commodity exports in total exports, and which are highly concentrated in exportable commodities with long-lived price shocks. 
How can these findings inform African policy-makers in reacting to a particular terms of trade shock in their country? Currently, the policy-maker probably has little information to assess whether the shock is likely to be short- or long-lived, which complicates projecting macroeconomic aggregates, and making policy decisions. We provide estimates of the median duration and variability of typical shocks that can be used, together with episode-specific knowledge of world price movements, to form a judgement of the likely duration of any given shock. The confidence intervals for shock persistence are important here, as there are some countries where shock duration is estimated relatively precisely, and others where the confidence intervals are wide, indicating a broad range of possible outcomes. Since the debt crisis of the $1980 \mathrm{~s}$, African countries have typically not had access to international capital markets for use in smoothing shocks. As a result, there is scope for domestic policy responses aimed at smoothing the path of national consumption in response to terms of trade shocks. This is particularly important for temporary positive shocks, where increased domestic savings out of a temporary windfall can raise current and future output. The shorter the expected period of the shock the higher should be the windfall savings rate. Particularly for the majority of countries with relatively short-lived shocks, our measures of shock persistence and their associated confidence intervals could be useful in informing domestic savings decisions. 
Descriptive Statistics, Net Barter Terms of Trade, Sub-Saharan Africa, 1960-96

\begin{tabular}{|c|c|c|c|c|}
\hline Country & Mean & Variance & Skewncss & Kurtosis \\
\hline Angola & 0.015 & 0.019 & $\begin{array}{c}0.731 \\
(0.086)\end{array}$ & $\begin{array}{c}4.771 \\
(0.000)\end{array}$ \\
\hline Benin & 4.849 & 0.059 & $\begin{array}{l}-0.212 \\
(0.612)\end{array}$ & $\begin{array}{l}-1.138 \\
(0.199)\end{array}$ \\
\hline Botswana & -0.009 & 0.016 & $\begin{array}{c}1.557 \\
(0.004)\end{array}$ & $\begin{array}{l}8.826 \\
(0.000)\end{array}$ \\
\hline Burkina Faso & 4.696 & 0.013 & $\begin{array}{l}-0.028 \\
(0.946)\end{array}$ & $\begin{array}{l}-0.497 \\
(0.575)\end{array}$ \\
\hline Burundi & 4.759 & 0.216 & $\begin{array}{l}-0.583 \\
(0.274)\end{array}$ & $\begin{array}{l}0.485 \\
(0.677)\end{array}$ \\
\hline Cameroon & -0.010 & 0.015 & $\begin{array}{c}1.196 \\
(0.005)\end{array}$ & $\begin{array}{c}3.834 \\
(0.000)\end{array}$ \\
\hline Central African Republic & 4.573 & 0.013 & $\begin{array}{c}0.375 \\
(0.371)\end{array}$ & $\begin{array}{l}-0.856 \\
(0.334)\end{array}$ \\
\hline Chad & 4.455 & 0.037 & $\begin{array}{l}-0.199 \\
(0.635)\end{array}$ & $\begin{array}{l}-1.412 \\
(0.112)\end{array}$ \\
\hline Comoros & 4.957 & 0.108 & $\begin{array}{l}-0.487 \\
(0.361)\end{array}$ & $\begin{array}{l}-1.356 \\
(0.244)\end{array}$ \\
\hline Congo, Democratic Republic of & 4.804 & 0.067 & $\begin{array}{c}0.514 \\
(0.220)\end{array}$ & $\begin{array}{l}-0.368 \\
(0.678)\end{array}$ \\
\hline Congo & 0.041 & 0.049 & $\begin{array}{l}2.734 \\
(0.000)\end{array}$ & $\begin{array}{l}14.839 \\
(0.000)\end{array}$ \\
\hline Côte d'Ivoire & -0.002 & 0.009 & $\begin{array}{c}1.762 \\
(0.000)\end{array}$ & $\begin{array}{l}5.547 \\
(0.000)\end{array}$ \\
\hline Equatorial Guinea & 4.572 & 0.106 & $\begin{array}{l}-0.019 \\
(0.970)\end{array}$ & $\begin{array}{l}-0.215 \\
(0.853)\end{array}$ \\
\hline Ethiopia & 4.895 & 0.127 & $\begin{array}{l}-0.637 \\
(0.129)\end{array}$ & $\begin{array}{l}-0.928 \\
(0.296)\end{array}$ \\
\hline Gabon & 0.035 & 0.052 & $\begin{array}{l}2.003 \\
(0.000)\end{array}$ & $\begin{array}{c}9.603 \\
(0.000)\end{array}$ \\
\hline Gambia & 4.942 & 0.052 & $\begin{array}{l}-0.388 \\
(0.355)\end{array}$ & $\begin{array}{l}-0.868 \\
(0.328)\end{array}$ \\
\hline Ghana & 4.629 & 0.098 & $\begin{array}{c}0.560 \\
(0.182)\end{array}$ & $\begin{array}{c}0.858 \\
(0.333)\end{array}$ \\
\hline Guinea & 4.840 & 0.047 & $\begin{array}{l}-0.410 \\
(0.442)\end{array}$ & $\begin{array}{l}-1.266 \\
(0.277)\end{array}$ \\
\hline Guinea Bissau & 4.338 & 0.069 & $\begin{array}{l}-1.153 \\
(0.031)\end{array}$ & $\begin{array}{c}1.081 \\
(0.353)\end{array}$ \\
\hline Kenya & -0.009 & 0.008 & $\begin{array}{l}0.230 \\
(0.482)\end{array}$ & $\begin{array}{c}1.304 \\
(0.148)\end{array}$ \\
\hline Liberia & 4.909 & 0.110 & $\begin{array}{c}0.982 \\
(0.019)\end{array}$ & $\begin{array}{c}0.179 \\
(0.840)\end{array}$ \\
\hline Madagascar & 4.664 & 0.034 & $\begin{array}{l}-0.938 \\
(0.025)\end{array}$ & $\begin{array}{l}-0.137 \\
(0.877)\end{array}$ \\
\hline Malawi & 4.733 & 0.031 & $\begin{array}{c}0.022 \\
(0.958) \\
\end{array}$ & $\begin{array}{l}-0.926 \\
(0.297) \\
\end{array}$ \\
\hline
\end{tabular}


Descriptive Statistics, Net Barter Terms of Trade, Sub-Saharan Africa, 1960-96 (Concluded)

\begin{tabular}{|c|c|c|c|c|}
\hline Country & Mean & Variance & Skewness & Kurtosis \\
\hline Mali & 4.611 & 0.006 & $\begin{array}{c}0.177 \\
(0.673)\end{array}$ & $\begin{array}{l}-0.578 \\
(0.515)\end{array}$ \\
\hline Mauritania & -0.021 & 0.005 & $\begin{array}{c}0.131 \\
(0.759)\end{array}$ & $\begin{array}{c}0.821 \\
(0.363)\end{array}$ \\
\hline Mauritius & 4.603 & 0.037 & $\begin{array}{c}0.962 \\
(0.022)\end{array}$ & $\begin{array}{c}1.278 \\
(0.150)\end{array}$ \\
\hline Mozambique & 4.759 & 0.005 & $\begin{array}{c}0.730 \\
(0.082)\end{array}$ & $\begin{array}{c}1.595 \\
(0.072)\end{array}$ \\
\hline Niger & 4.829 & 0.057 & $\begin{array}{l}-0.004 \\
(0.992)\end{array}$ & $\begin{array}{l}-1.539 \\
(0.083)\end{array}$ \\
\hline Nigeria & 0.029 & 0.047 & $\begin{array}{c}0.867 \\
(0.042)\end{array}$ & $\begin{array}{c}6.180 \\
(0.000)\end{array}$ \\
\hline Rwanda & 4.809 & 0.101 & $\begin{array}{l}-0.079 \\
(0.850)\end{array}$ & $\begin{array}{c}0.615 \\
(0.488)\end{array}$ \\
\hline São Tomé and Principe & 4.881 & 0.106 & $\begin{array}{l}-0.082 \\
(0.877)\end{array}$ & $\begin{array}{l}-0.386 \\
(0.740)\end{array}$ \\
\hline Senegal & 4.611 & 0.036 & $\begin{array}{c}0.470 \\
(0.263)\end{array}$ & $\begin{array}{c}0.012 \\
(0.989)\end{array}$ \\
\hline Seychelles & 4.979 & 0.058 & $\begin{array}{l}-0.603 \\
(0.258)\end{array}$ & $\begin{array}{c}0.193 \\
(0.868)\end{array}$ \\
\hline Sicrra Leone & 4.735 & 0.028 & $\begin{array}{l}-0.432 \\
(0.304)\end{array}$ & $\begin{array}{l}-1.088 \\
(0.220)\end{array}$ \\
\hline Somalia & 4.707 & 0.037 & $\begin{array}{c}0.296 \\
(0.481)\end{array}$ & $\begin{array}{l}-1.233 \\
(0.165)\end{array}$ \\
\hline South Africa & -0.017 & 0.003 & $\begin{array}{c}0.262 \\
(0.615)\end{array}$ & $\begin{array}{l}-0.331 \\
(0.771)\end{array}$ \\
\hline Sudan & 4.790 & 0.016 & $\begin{array}{c}0.457 \\
(0.276)\end{array}$ & $\begin{array}{c}0.122 \\
(0.890)\end{array}$ \\
\hline Tanzania & 4.807 & 0.042 & $\begin{array}{l}-0.615 \\
(0.143)\end{array}$ & $\begin{array}{l}-0.158 \\
(0.859)\end{array}$ \\
\hline Togo & 4.775 & 0.133 & $\begin{array}{c}1.840 \\
(0.000)\end{array}$ & $\begin{array}{c}3.202 \\
(0.000)\end{array}$ \\
\hline Uganda & -0.024 & 0.038 & $\begin{array}{l}-0.027 \\
(0.949)\end{array}$ & $\begin{array}{c}2.199 \\
(0.015)\end{array}$ \\
\hline Zambia & 4.858 & 0.142 & $\begin{array}{c}0.540 \\
(0.198)\end{array}$ & $\begin{array}{l}-0.486 \\
(0.584)\end{array}$ \\
\hline Zimbabwe & 4.718 & 0.037 & $\begin{array}{r}0.610 \\
(0.253) \\
\end{array}$ & $\begin{array}{l}-0.193 \\
(0.868) \\
\end{array}$ \\
\hline
\end{tabular}

Noles: The net barter terms of trade (NBTT) data for all countries is annual and runs from 1960-96, all with base year 1987=100, excepting: Botswana, Burundi, Comoros, Equatorial Guinea, Guinea, Guinea-Bissau, South Africa and Zimbabwe (all 1970-93). The variable (described in Section IV) is the logarithm of the NBTT index, except for those countries which exhibit permanent shocks to their NBTT (those in the final column of 'Table 3), where the variable is the first difference of the logarithm of the NBTT index. The statistics are sample moments. The numbers in parentheses are probability values under the null hypothesis of normality. The skewness and kurtosis formulae, and the test statistics based upon them, are taken from Kendall and Stuart (1958). 


\section{Results of Median-Unbiased Autoregressive/Unit Root Estimation, Net Barter Terms of Trade, Sub-Saharan Africa, 1960-96}

\begin{tabular}{|c|c|c|c|c|c|c|c|}
\hline Country & Estimator & $\alpha$ & $\operatorname{IR}(4)$ & $\operatorname{IR}(12)$ & $\operatorname{IR}(36)$ & CIR & HILS \\
\hline Angola & $\begin{array}{c}\text { LS } \\
\text { Median- } \\
\text { Unbiased }\end{array}$ & $\begin{array}{c}0.881 \\
1.000 \\
{[0.871-1.000]}\end{array}$ & $\begin{array}{c}0.602 \\
1.000 \\
{[0.575-1.000]}\end{array}$ & $\begin{array}{c}0.219 \\
1.000 \\
{[0.190-1.000]}\end{array}$ & $\begin{array}{c}0.010^{-} \\
1.000^{-} \\
{[0.007-1.000]}\end{array}$ & $\begin{array}{c}8.403 \\
1.000 \\
{[7.742-\infty]}\end{array}$ & $\begin{array}{c}5.471 \\
\infty \\
{[5.011-\infty]}\end{array}$ \\
\hline Benin & $\begin{array}{c}\text { LS } \\
\text { Median- } \\
\text { Unbiased }\end{array}$ & $\begin{array}{c}0.478 \\
0.582 \\
{[0.318-0.904]}\end{array}$ & $\begin{array}{c}0.052 \\
0.114 \\
{[0.010-0.668]}\end{array}$ & $\begin{array}{c}0.000 \\
0.001 \\
{[0.000-0.298]}\end{array}$ & $\begin{array}{c}0.000 \\
0.000 \\
{[0.000-0.027]}\end{array}$ & $\begin{array}{c}1.916 \\
0.000 \\
{[1.466+10.428]}\end{array}$ & $\begin{array}{c}0.939 \\
1.279 \\
{[0.605-6.875]}\end{array}$ \\
\hline Botswana & $\begin{array}{c}\text { LS } \\
\text { Median- } \\
\text { Unbiased }\end{array}$ & $\begin{array}{c}0.811 \\
1.000 \\
{[0.759-1.000]}\end{array}$ & $\begin{array}{c}0.433 \\
1.000 \\
{[0.333-1.000]}\end{array}$ & $\begin{array}{c}0.081 \\
1.000 \\
{[0.037-1.000]}\end{array}$ & $\begin{array}{c}0.000 \\
1.000 \\
{[0.000-1.000]}\end{array}$ & $\begin{array}{c}5.291 \\
\infty \\
{[4.157-\infty]}\end{array}$ & $\begin{array}{c}3.309 \\
\infty \\
{[2.519-\infty]}\end{array}$ \\
\hline Burkina Faso & $\begin{array}{c}\text { LS } \\
\text { Median- } \\
\text { Unbiased }\end{array}$ & $\begin{array}{c}0.606 \\
0.729 \\
{[0.479-1.000]}\end{array}$ & $\begin{array}{c}0.135 \\
0.283 \\
{[0.053-1.000]}\end{array}$ & $\begin{array}{c}0.002 \\
0.023 \\
{[0.000-1.000]}\end{array}$ & $\begin{array}{c}0.000 \\
0.000 \\
{[0.000-1.000]}\end{array}$ & $\begin{array}{c}2.538 \\
3.692 \\
{[1.918-\infty]}\end{array}$ & $\begin{array}{c}1.384 \\
2.194 \\
{[0.941 * \infty]}\end{array}$ \\
\hline Burundi & $\begin{array}{c}\text { LS } \\
\text { Median- } \\
\text { Unbiased }\end{array}$ & $\begin{array}{c}0.575 \\
0.692 \\
{[0.439-1.000]}\end{array}$ & $\begin{array}{c}0.109 \\
0.229 \\
{[0.037-1.000]}\end{array}$ & $\begin{array}{c}0.001 \\
0.012 \\
{[0.000-1.000]}\end{array}$ & $\begin{array}{c}0.000 \\
0.000 \\
{[0.000-1.000]}\end{array}$ & $\begin{array}{c}2.353 \\
3.242 \\
{[1.782-\infty]}\end{array}$ & $\begin{array}{c}1.253 \\
1.879 \\
{[0.841-\infty]}\end{array}$ \\
\hline Cameroon & $\begin{array}{c}\text { LS } \\
\text { Median- } \\
\text { Unbiased }\end{array}$ & $\begin{array}{c}0.825 \\
1.000 \\
{[0.781-1.000]}\end{array}$ & $\begin{array}{c}0.463 \\
1.000 \\
{[0.373-1.000]}\end{array}$ & $\begin{array}{c}0.099 \\
1.000 \\
{[0.052-1.000]}\end{array}$ & $\begin{array}{c}0.000 \\
1.000 \\
{[0.000-1.000]}\end{array}$ & $\begin{array}{c}5.714 \\
\infty \\
{[4.573-\infty]}\end{array}$ & $\begin{array}{c}3.603 \\
\infty \\
{[2.809-\infty]}\end{array}$ \\
\hline $\begin{array}{l}\text { Central } \\
\text { African } \\
\text { Republic }\end{array}$ & $\begin{array}{c}\text { LS } \\
\text { Median- } \\
\text { Unbiased }\end{array}$ & $\begin{array}{c}0.645 \\
0.776 \\
{[0.529-1.000]}\end{array}$ & $\begin{array}{c}0.173 \\
0.362 \\
{[0.078-1.000]}\end{array}$ & $\begin{array}{c}0.005 \\
0.047 \\
{[0.000-1.000]}\end{array}$ & $\begin{array}{c}0.000 \\
0.000 \\
{[0.000-1.000]}\end{array}$ & $\begin{array}{c}2.817 \\
4.455 \\
{[2.121-\infty]}\end{array}$ & $\begin{array}{c}1.581 \\
2.727 \\
{[1.087-\infty]}\end{array}$ \\
\hline Chad & $\begin{array}{c}\text { LS } \\
\text { Median- } \\
\text { Unbiased }\end{array}$ & $\begin{array}{c}0.683 \\
0.823 \\
{[0.579-1.000]}\end{array}$ & $\begin{array}{c}0.218 \\
0.460 \\
{[0.113-1.000]}\end{array}$ & $\begin{array}{c}0.010 \\
0.097 \\
{[0.001-1.000]}\end{array}$ & $\begin{array}{c}0.000 \\
0.001 \\
{[0.000-1.000]}\end{array}$ & $\begin{array}{c}3.155 \\
5.664 \\
{[2.377-\infty]}\end{array}$ & $\begin{array}{c}1.818 \\
3.568 \\
{[1.270-\infty]}\end{array}$ \\
\hline Comoros & $\begin{array}{c}\text { LS } \\
\text { Median- } \\
\text { Unbiased }\end{array}$ & $\begin{array}{c}0.370 \\
0.462 \\
{[0.188-0.769]}\end{array}$ & $\begin{array}{c}0.019 \\
0.045 \\
{[0.001-0.350]}\end{array}$ & $\begin{array}{c}0.000 \\
0.000 \\
{[0.000-0.043]}\end{array}$ & $\begin{array}{c}0.000 \\
0.000 \\
{[0.000-0.000]}\end{array}$ & $\begin{array}{c}1.587 \\
1.858 \\
{[1.232-4.333]}\end{array}$ & $\begin{array}{c}0.697 \\
0.897 \\
{[0.415-2.642]}\end{array}$ \\
\hline $\begin{array}{l}\text { Congo, } \\
\text { Democratic } \\
\text { Republic of }\end{array}$ & $\begin{array}{c}\text { LS } \\
\text { Median- } \\
\text { Unbiased }\end{array}$ & $\begin{array}{c}0.747 \\
0.912 \\
{[0.667-1.000]}\end{array}$ & $\begin{array}{c}0.311 \\
0.690 \\
{[0.197-1.000]}\end{array}$ & $\begin{array}{c}0.030 \\
0.329 \\
{[0.008-1.000]}\end{array}$ & $\begin{array}{c}0.000 \\
0.036 \\
{[0.000-1.000]}\end{array}$ & $\begin{array}{c}3.953 \\
11.305 \\
{[2.999-\infty]}\end{array}$ & $\begin{array}{c}2.376 \\
7.484 \\
{[1.709-\propto]}\end{array}$ \\
\hline Congo & $\begin{array}{c}\text { LS } \\
\text { Mcdian- } \\
\text { Unbiased }\end{array}$ & $\begin{array}{c}0.889 \\
1.000 \\
{[0.884-1.000]}\end{array}$ & $\begin{array}{c}0.625 \\
1.000 \\
{[0.611-1.000]}\end{array}$ & $\begin{array}{c}0.244 \\
1.000 \\
{[0.228-1.000]}\end{array}$ & $\begin{array}{c}0.014 \\
1.000 \\
{[0.012-1.000]}\end{array}$ & $\begin{array}{c}9.009 \\
\infty \\
{[8.639-\infty]}\end{array}$ & $\begin{array}{c}5.891 \\
\infty \\
{[5.634-\infty]}\end{array}$ \\
\hline Côte d'Ivoire & $\begin{array}{c}\text { LS } \\
\text { Median- } \\
\text { Unbiased }\end{array}$ & $\begin{array}{c}0.855 \\
1.000 \\
{[0.828-1.000]}\end{array}$ & $\begin{array}{c}0.534 \\
1.000 \\
{[0.470-1.000]}\end{array}$ & $\begin{array}{c}0.153 \\
1.000 \\
{[0.104-1.000]}\end{array}$ & $\begin{array}{c}0.003 \\
1.000 \\
{[0.001-1.000]}\end{array}$ & $\begin{array}{c}6.897 \\
\infty \\
{[5.810-\infty]}\end{array}$ & $\begin{array}{c}4.423 \\
\infty \\
{[3.670-\infty]}\end{array}$ \\
\hline $\begin{array}{l}\text { Equatorial } \\
\text { Guinea }\end{array}$ & $\begin{array}{c}\text { LS } \\
\text { Median- } \\
\text { Unbiased }\end{array}$ & $\begin{array}{c}0.422 \\
0.519 \\
{[0.251-0.831]}\end{array}$ & $\begin{array}{c}0.032 \\
0.073 \\
{[0.004-0.476]}\end{array}$ & $\begin{array}{c}0.000 \\
0.000 \\
{[0.000-0.108]}\end{array}$ & $\begin{array}{c}0.000 \\
0.000 \\
{[0.000-0.001]}\end{array}$ & $\begin{array}{c}1.730 \\
2.080 \\
{[1.335-5.903]}\end{array}$ & $\begin{array}{c}0.803 \\
1.057 \\
{[0.501-3.734]}\end{array}$ \\
\hline Ethiopia & $\begin{array}{c}\text { LS } \\
\text { Median- } \\
\text { Unbiased }\end{array}$ & $\begin{array}{c}0.666 \\
0.801 \\
{[0.557-1.000]}\end{array}$ & $\begin{array}{c}0.197 \\
0.412 \\
{[0.096-1.000]}\end{array}$ & $\begin{array}{c}0.008 \\
0.070 \\
{[0.001-1.000]}\end{array}$ & $\begin{array}{c}0.000 \\
0.000 \\
{[0.000-1.000]}\end{array}$ & $\begin{array}{c}2.994 \\
5.035 \\
{[2.256-\infty]}\end{array}$ & $\begin{array}{c}1.705 \\
3.131 \\
{[1.183-\infty]}\end{array}$ \\
\hline Gabon & $\begin{array}{c}\text { LS } \\
\text { Median- } \\
\text { Unbiased }\end{array}$ & $\begin{array}{c}0.893 \\
1.000 \\
{[0.891-1.000]}\end{array}$ & $\begin{array}{c}0.636 \\
1.000 \\
{[0.630-1.000]}\end{array}$ & $\begin{array}{c}0.257 \\
1.000 \\
{[0.250-1.000]}\end{array}$ & $\begin{array}{c}0.017 \\
1.000 \\
{[0.016-1.000]}\end{array}$ & $\begin{array}{c}9.346 \\
\infty \\
{[9.165-\infty]}\end{array}$ & $\begin{array}{c}6.125 \\
\infty \\
{[5.999-\infty]}\end{array}$ \\
\hline
\end{tabular}




\begin{tabular}{|c|c|c|c|c|c|c|c|}
\hline Country & Estimator & $\alpha$ & $\operatorname{IR}(4)$ & $\operatorname{IR}(12)$ & $\operatorname{IR}(36)$ & CIR & IIISS \\
\hline Gambia & $\begin{array}{c}\text { LS } \\
\text { Median- } \\
\text { Unbiased }\end{array}$ & $\begin{array}{c}0.501 \\
0.608 \\
{[0.347-0.945]}\end{array}$ & $\begin{array}{c}0.063 \\
0.137 \\
{[0.014-0.797]}\end{array}$ & $\begin{array}{c}0.000 \\
0.003 \\
{[0.000-0.506]}\end{array}$ & $\begin{array}{c}0.000 \\
0.000 \\
{[0.000-0.130]}\end{array}$ & $\begin{array}{c}2.004 \\
2.551 \\
{[1.531-18.118]}\end{array}$ & $\begin{array}{c}1.003 \\
1.393 \\
{[0.655-12.209]}\end{array}$ \\
\hline Ghana & $\begin{array}{c}\text { LS } \\
\text { Median- } \\
\text { Unbiased }\end{array}$ & $\begin{array}{c}0.847 \\
0.651 \\
{[0.491-0.765]}\end{array}$ & $\begin{array}{c}0.515 \\
0.180 \\
{[0.058-0.342]}\end{array}$ & $\begin{array}{c}0.136 \\
0.006 \\
{[0.000-0.040]}\end{array}$ & $\begin{array}{c}0.002 \\
0.000 \\
{[0.000-0.000]}\end{array}$ & $\begin{array}{c}6.536 \\
2.869 \\
{[1.965-4.255]}\end{array}$ & $\begin{array}{c}4.174 \\
1.617 \\
{[0.974-2.588]}\end{array}$ \\
\hline Guinea & $\begin{array}{c}\text { LS } \\
\text { Median- } \\
\text { Unbiased }\end{array}$ & $\begin{array}{c}0.705 \\
0.852 \\
{[0.608-1.000]}\end{array}$ & $\begin{array}{c}0.247 \\
0.526 \\
{[0.137-1.000]}\end{array}$ & $\begin{array}{c}0.015 \\
0.145 \\
{[0.003-1.000]}\end{array}$ & $\begin{array}{c}0.000 \\
0.003 \\
{[0.000-1.000]}\end{array}$ & $\begin{array}{c}3.390 \\
6.734 \\
{[2.554-\infty]}\end{array}$ & $\begin{array}{c}1.983 \\
4.312 \\
{[1.395-\infty]}\end{array}$ \\
\hline Guinea Bissau & $\begin{array}{c}\text { LS } \\
\text { Median- } \\
\text { Unbiased }\end{array}$ & $\begin{array}{c}0.575 \\
0.691 \\
{[0.439-1.000]}\end{array}$ & $\begin{array}{c}0.109 \\
0.229 \\
{[0.037-1.000]}\end{array}$ & $\begin{array}{c}0.001 \\
0.012 \\
{[0.000-1.000]}\end{array}$ & $\begin{array}{c}0.000 \\
0.000 \\
{[0.000-1.000]}\end{array}$ & $\begin{array}{c}2.353 \\
3.241 \\
{[1.781-\infty]}\end{array}$ & $\begin{array}{c}1.253 \\
1.879 \\
{[0.841-\infty]}\end{array}$ \\
\hline Kenya & $\begin{array}{c}\text { LS } \\
\text { Median- } \\
\text { Unbiased }\end{array}$ & $\begin{array}{c}0.846 \\
1.000 \\
{[0.814-1.000]}\end{array}$ & $\begin{array}{c}0.512 \\
1.000 \\
{[0.438-1.000]}\end{array}$ & $\begin{array}{c}0.134 \\
1.000 \\
{[0.084-1.000]}\end{array}$ & $\begin{array}{c}0.002 \\
1.000 \\
{[0.001-1.000]}\end{array}$ & $\begin{array}{c}6.494 \\
\infty \\
{[5.368-\infty]}\end{array}$ & $\begin{array}{c}4.145 \\
\infty \\
{[3.362-\infty]}\end{array}$ \\
\hline I, sberia & $\begin{array}{c}\text { LS } \\
\text { Median- } \\
\text { Unbiased }\end{array}$ & $\begin{array}{c}0.777 \\
0.974 \\
{[0.709-1.000]}\end{array}$ & $\begin{array}{c}0.364 \\
0.901 \\
{[0.253-1.000]}\end{array}$ & $\begin{array}{c}0.048 \\
0.732 \\
{[0.016-1.000]}\end{array}$ & $\begin{array}{c}0.000 \\
0.393 \\
{[0.000-1.000]}\end{array}$ & $\begin{array}{c}4.484 \\
39.015 \\
{[3.438-\infty]}\end{array}$ & $\begin{array}{c}2.747 \\
26.695 \\
{[2.016-\infty]}\end{array}$ \\
\hline Madagascar & $\begin{array}{c}\text { LS } \\
\text { Median- } \\
\text { Unbiased }\end{array}$ & $\begin{array}{c}0.710 \\
0.859 \\
{[0.616-1.000]}\end{array}$ & $\begin{array}{c}0.254 \\
0.544 \\
{[0.144-1.000]}\end{array}$ & $\begin{array}{c}0.016 \\
0.161 \\
{[0.003-1.000]}\end{array}$ & $\begin{array}{c}0.000 \\
0.004 \\
{[0.000-1.000]}\end{array}$ & $\begin{array}{c}3.448 \\
7.083 \\
{[2.603-\infty]}\end{array}$ & $\begin{array}{c}2.024 \\
4.554 \\
{[1.429-\infty]}\end{array}$ \\
\hline Malawi & $\begin{array}{c}\text { LS } \\
\text { Mcdian- } \\
\text { Unbiased }\end{array}$ & $\begin{array}{c}0.504 \\
0.612 \\
{[0.351-0.951]}\end{array}$ & $\begin{array}{c}0.064 \\
0.140 \\
{[0.015-0.819]}\end{array}$ & $\begin{array}{c}0.000 \\
0.003 \\
{[0.000-0.550]}\end{array}$ & $\begin{array}{c}0.000 \\
0.000 \\
{[0.000-0.166]}\end{array}$ & $\begin{array}{c}2.016 \\
2.574 \\
{[1.540-20.574]}\end{array}$ & $\begin{array}{c}1.011 \\
1.410 \\
{[0.662-13.911]}\end{array}$ \\
\hline Mali & $\begin{array}{c}\text { LS } \\
\text { Median- } \\
\text { Unbiased }\end{array}$ & $\begin{array}{c}0.443 \\
0.543 \\
{[0.276-0.857]}\end{array}$ & $\begin{array}{c}0.039 \\
0.087 \\
{[0.006-0.539]}\end{array}$ & $\begin{array}{c}0.000 \\
0.001 \\
{[0.000-0.157]}\end{array}$ & $\begin{array}{c}0.000 \\
0.000 \\
{[0.000-0.004]}\end{array}$ & $\begin{array}{c}1.795 \\
2.188 \\
{[1.381-6.992]}\end{array}$ & $\begin{array}{c}0.851 \\
1.135 \\
{[0.539-4.491]}\end{array}$ \\
\hline Mauritania & $\begin{array}{c}\text { LS } \\
\text { Median- } \\
\text { Unbiased }\end{array}$ & $\begin{array}{c}0.848 \\
1.000 \\
{[0.816-1.000]}\end{array}$ & $\begin{array}{c}0.517 \\
1.000 \\
{[0.443-1.000]}\end{array}$ & $\begin{array}{c}0.138 \\
1.000 \\
{[0.087-1.000]}\end{array}$ & $\begin{array}{c}0.003 \\
1.000 \\
{[0.001-1.000]}\end{array}$ & $\begin{array}{c}6.579 \\
\infty \\
{[5.431-\infty]}\end{array}$ & $\begin{array}{c}4.204 \\
\infty \\
{[3.406-\infty]}\end{array}$ \\
\hline Mauritius & $\begin{array}{c}\text { LS } \\
\text { Median- } \\
\text { Unbiased }\end{array}$ & $\begin{array}{c}0.677 \\
0.816 \\
{[0.571-1.000]}\end{array}$ & $\begin{array}{c}0.210 \\
0.443 \\
{[0.107-1.000]}\end{array}$ & $\begin{array}{c}0.009 \\
0.087 \\
{[0.001-1.000]}\end{array}$ & $\begin{array}{c}0.000 \\
0.001 \\
{[0.000-1.000]}\end{array}$ & $\begin{array}{c}3.095 \\
5.424 \\
{[2.333-\infty]}\end{array}$ & $\begin{array}{c}1.777 \\
3.401 \\
{[1.238-\infty]}\end{array}$ \\
\hline Mozambique & $\begin{array}{c}\text { LS } \\
\text { Median- } \\
\text { Unbiased }\end{array}$ & $\begin{array}{c}0.392 \\
0.486 \\
{[0.214-0.794]}\end{array}$ & $\begin{array}{c}0.024 \\
0.056 \\
{[0.002-0.398]}\end{array}$ & $\begin{array}{c}0.000 \\
0.000 \\
{[0.000-0.063]}\end{array}$ & $\begin{array}{c}0.000 \\
0.000 \\
{[0.000-0.000]}\end{array}$ & $\begin{array}{c}1.645 \\
1.944 \\
{[1.273-4.860]}\end{array}$ & $\begin{array}{c}0.740 \\
0.960 \\
{[0.450-3.009]}\end{array}$ \\
\hline Niger & $\begin{array}{c}\text { LS } \\
\text { Mcdian- } \\
\text { Unbiased }\end{array}$ & $\begin{array}{c}0.674 \\
0.812 \\
{[0.567-1.000]}\end{array}$ & $\begin{array}{c}0.206 \\
0.434 \\
{[0.103-1.000]}\end{array}$ & $\begin{array}{c}0.009 \\
0.082 \\
{[0.001-1.000]}\end{array}$ & $\begin{array}{c}0.000 \\
0.001 \\
{[0.000-1.000]}\end{array}$ & $\begin{array}{c}3.067 \\
5.306 \\
{[2.310-\infty]}\end{array}$ & $\begin{array}{c}1.757 \\
3.319 \\
{[1.222-\infty]}\end{array}$ \\
\hline Nigeria & $\begin{array}{c}\text { LS } \\
\text { Median- } \\
\text { Unbiased }\end{array}$ & $\begin{array}{c}0.913 \\
1.000 \\
{[0.929-1.000]}\end{array}$ & $\begin{array}{c}0.695 \\
] .000 \\
{[0.745-1.000]}\end{array}$ & $\begin{array}{c}0.335 \\
1.000 \\
{[0.414-1.000]}\end{array}$ & $\begin{array}{c}0.038 \\
1.000 \\
{[0.071-1.000]}\end{array}$ & $\begin{array}{c}11.494 \\
\infty \\
{[14.100-\infty]}\end{array}$ & $\begin{array}{c}7.615 \\
\infty \\
{[9.422-\infty]}\end{array}$ \\
\hline Rwanda & $\begin{array}{c}\text { LS } \\
\text { Median- } \\
\text { Unbiased }\end{array}$ & $\begin{array}{c}0.797 \\
0.592 \\
{[0.429-0.715]}\end{array}$ & $\begin{array}{c}0.404 \\
0.123 \\
{[0.034-0.261]}\end{array}$ & $\begin{array}{c}0.066 \\
0.002 \\
{[0.000-0.018]}\end{array}$ & $\begin{array}{c}0.000 \\
0.000 \\
10.000-0.000]\end{array}$ & $\begin{array}{c}4.926 \\
2.451 \\
{[1.750-3.506]}\end{array}$ & $\begin{array}{c}3.055 \\
1.322 \\
{[0.818-2.064]}\end{array}$ \\
\hline $\begin{array}{l}\text { São Tomé and } \\
\text { Principe }\end{array}$ & $\begin{array}{c}\text { LS } \\
\text { Median- } \\
\text { Unbiased }\end{array}$ & $\begin{array}{c}0.438 \\
0.537 \\
{[0.270-0.850]}\end{array}$ & $\begin{array}{c}0.037 \\
0.083 \\
{[0.005-0.522]}\end{array}$ & $\begin{array}{c}0.000 \\
0.001 \\
{[0.000-0.142]}\end{array}$ & $\begin{array}{c}0.000 \\
0.003 \\
{[0.000-0.003]}\end{array}$ & $\begin{array}{c}1.779 \\
2.161 \\
{[1.370-6.672]}\end{array}$ & $\begin{array}{c}0.840 \\
1.115 \\
{[0.529-4.269]}\end{array}$ \\
\hline
\end{tabular}




\begin{tabular}{|c|c|c|c|c|c|c|c|}
\hline Country & Estimator & $\alpha$ & $\mathbb{R}(4)$ & $\operatorname{IR}(12)$ & $\operatorname{IR}(36)$ & $\mathrm{ClR}$ & HLS \\
\hline Sencgal & $\begin{array}{c}\text { LS } \\
\text { Median- } \\
\text { Unbiased }\end{array}$ & $\begin{array}{c}0.703 \\
0.849 \\
{[0.606-1.000]}\end{array}$ & $\begin{array}{c}0.244 \\
0.520 \\
{[0.135-1.000]}\end{array}$ & $\begin{array}{c}0.015 \\
0.141 \\
{[0.002-1.000]}\end{array}$ & $\begin{array}{c}0.000 \\
0.003 \\
{[0.000-1.000]}\end{array}$ & $\begin{array}{c}3.367 \\
6.630 \\
{[2.538-\infty]}\end{array}$ & $\begin{array}{c}1.967 \\
4.240 \\
{[1.384-\infty]}\end{array}$ \\
\hline Seychelles & $\begin{array}{c}\text { LS } \\
\text { Median- } \\
\text { Unbiased }\end{array}$ & $\begin{array}{c}0.447 \\
0.548 \\
{[0.281-0.863]}\end{array}$ & $\begin{array}{c}0.039 \\
0.090 \\
{[0.006-0.554]}\end{array}$ & $\begin{array}{c}0.000 \\
0.001 \\
{[0.000-0.170]}\end{array}$ & $\begin{array}{c}0.000 \\
0.000 \\
{[0.000-1.000] .}\end{array}$ & $\begin{array}{c}1.808 \\
2.211 \\
{[1.391-7.287]}\end{array}$ & $\begin{array}{c}0.861 \\
1.151 \\
{[0.546-4.696]}\end{array}$ \\
\hline Sierra Leone & $\begin{array}{l}\text { LS } \\
\text { Median- } \\
\text { Unbiased }\end{array}$ & $\begin{array}{c}0.661 \\
0.795 \\
{[0.550-1.000]}\end{array}$ & $\begin{array}{c}0.191 \\
0.399 \\
{[0.091-1.000]}\end{array}$ & $\begin{array}{c}0.007 \\
0.064 \\
{[0.001-1.000]}\end{array}$ & $\begin{array}{c}0.000 \\
0.000 \\
{[0.000-1.000]}\end{array}$ & $\begin{array}{c}2.950 \\
4.876 \\
{[2.221-\infty]}\end{array}$ & $\begin{array}{c}1.674 \\
3.020 \\
{[1.158-\infty]}\end{array}$ \\
\hline Somalia & $\begin{array}{c}\text { LS } \\
\text { Median- } \\
\text { Unbiased }\end{array}$ & $\begin{array}{c}0.556 \\
0.671 \\
{[0.416-1.000]}\end{array}$ & $\begin{array}{c}0.096 \\
0.203 \\
{[0.030-1.000]}\end{array}$ & $\begin{array}{c}0.001 \\
0.008 \\
{[0.000-1.000]}\end{array}$ & $\begin{array}{c}0.000 \\
0.000 \\
{[0.000-1.000]}\end{array}$ & $\begin{array}{c}2.252 \\
3.039 \\
{[1.712-\infty]}\end{array}$ & $\begin{array}{c}1.181 \\
1.737 \\
{[0.790-\infty]}\end{array}$ \\
\hline South Africa & $\begin{array}{c}\text { LS } \\
\text { Median- } \\
\text { Unbiased }\end{array}$ & $\begin{array}{c}0.933 \\
1.000 \\
{[0.984-1.000]}\end{array}$ & $\begin{array}{c}0.758 \\
1.000 \\
{[0.936-1.000]}\end{array}$ & $\begin{array}{c}0.435 \\
1.000 \\
{[0.821-1.000]}\end{array}$ & $\begin{array}{c}0.082 \\
1.000 \\
{[0.533-1.000]}\end{array}$ & $\begin{array}{c}14.925 \\
\infty \\
{[61.249-\infty]}\end{array}$ & $\begin{array}{c}9.995 \\
\infty \\
{[42.107-\infty]}\end{array}$ \\
\hline Sudan & $\begin{array}{c}\text { LS } \\
\text { Mcdian- } \\
\text { Unbiased }\end{array}$ & $\begin{array}{c}0.774 \\
0.965 \\
{[0.704-1.000]}\end{array}$ & $\begin{array}{c}0.359 \\
0.866 \\
{[0.245-1.000]}\end{array}$ & $\begin{array}{c}0.046 \\
0.649 \\
{[0.015-1.000]}\end{array}$ & $\begin{array}{c}0.000 \\
0.273 \\
{[0.000-1.000]}\end{array}$ & $\begin{array}{c}4.425 \\
28.271 \\
{[3.377-\infty]}\end{array}$ & $\begin{array}{c}2.706 \\
19.247 \\
{[1.974-\infty]}\end{array}$ \\
\hline Tanzania & $\begin{array}{c}\text { LS } \\
\text { Median- } \\
\text { Unbiased }\end{array}$ & $\begin{array}{c}0.772 \\
0.961 \\
{[0.702-1.000]}\end{array}$ & $\begin{array}{c}0.355 \\
0.854 \\
{[0.242-1.000]}\end{array}$ & $\begin{array}{c}0.045 \\
0.623 \\
{[0.014-1.000]}\end{array}$ & $\begin{array}{c}0.000 \\
0.241 \\
{[0.000-1.000]}\end{array}$ & $\begin{array}{c}4.386 \\
25.821 \\
{[3.351-\infty]}\end{array}$ & $\begin{array}{c}2.679 \\
17.549 \\
{[1.956-\infty]}\end{array}$ \\
\hline Togo & $\begin{array}{c}\text { LS } \\
\text { Median- } \\
\text { Unbiased }\end{array}$ & $\begin{array}{c}0.805 \\
0.570 \\
{[0.407-0.696]}\end{array}$ & $\begin{array}{c}0.420 \\
0.106 \\
{[0.027-0.235]}\end{array}$ & $\begin{array}{c}0.074 \\
0.001 \\
{[0.000-0.013]}\end{array}$ & $\begin{array}{c}0.000 \\
0.000 \\
{[0.000-0.000]}\end{array}$ & $\begin{array}{c}5.128 \\
2.328 \\
{[1.685-3.288]}\end{array}$ & $\begin{array}{c}3.196 \\
1.235 \\
{[0.770-1.912]}\end{array}$ \\
\hline Uganda & $\begin{array}{c}\text { LS } \\
\text { Median- } \\
\text { Unbiased }\end{array}$ & $\begin{array}{c}0.807 \\
1.000 \\
{[0.754-1.000]}\end{array}$ & $\begin{array}{c}0.424 \\
1.000 \\
{[0.323-1.000]}\end{array}$ & $\begin{array}{c}0.076 \\
1.000 \\
{[0.034-1.000]}\end{array}$ & $\begin{array}{c}0.000 \\
1.000 \\
{[0.000-1.000]}\end{array}$ & $\begin{array}{c}5.181 \\
\infty \\
{[4.067-\infty]}\end{array}$ & $\begin{array}{c}3.232 \\
\infty \\
{[2.456-\infty]}\end{array}$ \\
\hline Zambia & $\begin{array}{c}\text { LS } \\
\text { Median- } \\
\text { Unbiased }\end{array}$ & $\begin{array}{c}0.748 \\
0.914 \\
{[0.669-1.000]}\end{array}$ & $\begin{array}{c}0.313 \\
0.698 \\
{[0.200-1.000]}\end{array}$ & $\begin{array}{c}0.031 \\
0.340 \\
{[0.008-1.000]}\end{array}$ & $\begin{array}{c}0.000 \\
0.039 \\
{[0.000-1.000]}\end{array}$ & $\begin{array}{c}3.968 \\
11.636 \\
{[3.018-\infty]}\end{array}$ & $\begin{array}{c}2.387 \\
7.714 \\
{[1.722-\infty]}\end{array}$ \\
\hline 7imbabwe & $\begin{array}{c}\text { LS } \\
\text { Median- } \\
\text { Unbiased }\end{array}$ & $\begin{array}{c}0.352 \\
0.441 \\
{[0.167-0.748]}\end{array}$ & $\begin{array}{c}0.015 \\
0.038 \\
{[0.001-0.313]}\end{array}$ & $\begin{array}{c}0.000 \\
0.000 \\
{[0.000-0.031]}\end{array}$ & $\begin{array}{c}0.000 \\
0.000 \\
{[0.000-0.000]}\end{array}$ & $\begin{array}{c}1.543 \\
1.790 \\
{[1.200-3.967]}\end{array}$ & $\begin{array}{c}0.664 \\
0.848 \\
{[0.387-2.386]}\end{array}$ \\
\hline
\end{tabular}

Source: Authors' calculations.

Notes: The results of this table are based on Andrcws (1993)--see equation (1). The time series analyzed in the autoregressive/unit root model is the net barter terms of trade (NBTT), which is an index number formed as the price deflator of exports of goods divided by the price deflator of imports of goods, and is taken from the World Bank's World Development Indicators database. The data are expressed in logarithmic form. The NBTT data for all countries run from 1960-96, all with base year 1987=100, excepting: Botswana, Burundi, Comoros, Equatorial Guinea, Guinea, Guinea-Bissau, South Africa and Zimbabwe (all 1970-93).

$\operatorname{IR}(h)$ denotes the impuise response function at time horizon $h$. CIR denotes the cumulativc impulse response. HI.S is, for the autoregressive parameter $\alpha>0$, the length of time until the impulse response of a unit shock to an cconomic time series is half its initial magnitude. The entries in the rows labeled LS are the estimates of $\alpha, \operatorname{IR}(h)$, CIR and HLS obtained using the least squares estimates of $\alpha$ from the regression equation (1). The entries in the rows labeled median-unbiased are the median-unbiased estimates $\hat{\alpha}, I \hat{R}(h), C \hat{R}$ and $H \hat{L} S$ of $\alpha, \operatorname{IR}(h), \mathrm{CIR}$ and HLS, respectively, as defined in Section III. The intervals in square brackets below the median-unbiased estimates are the 90 percent confidence intervals. The median-unbiased estimates and exact confidence intervals given in this table were determined using quantiles generated by Andrews (1993) and by interpolation.

The Zivot-Andrews (1992) test for structural break found there was a significant regime change for three NBTT series: Ghana, Rwanda and Togo. For these three countries, the corrected median-unbiased estimate of the autoregressive parameter $(\alpha)$ are calculated using the results of McDermott (1994), and the median-unbiased estimates $\hat{\alpha}, l \hat{R}(h), C \hat{I} R$ and $H \hat{L} S$ of $\alpha, \operatorname{IR}(h), \operatorname{CIR}$ and HLS, respectively, use this corrected $\alpha$. 


\section{Persistence of Terms of Trade Shocks-Case Study of Uganda}

To explore the factors that the persistence of NBTT shocks depends on, and as a check of the robustness of our results, we examined in greater detail the persistence of shocks to the major exports and imports of an important SSA country, Uganda. Uganda's NBTT is disaggregated into the separate indices of real export and import unit values, and then each of these indices is disaggregated further into the real price indices of major exports and imports. The major commodity data used in this Appendix are quarterly real price indices, formed as the logarithm of the ratio of nominal prices of major imports and exports (defined in U.S. dollars per kilogram), deflated by the index of manufacturing unit values (base year 1990) for the period $1966: 1$ to $1998: 2 .^{37}$

For Uganda, on the export side shocks to coffee and 'other exports' are permanent; those to cotton, copper and tea have HLS of 4.9, 7.2 and 5.1 quarters, respectively; and those to tobacco, hides and maize have HLS of $1.5,0.9$ and 1.5 quarters, respectively. On the import side, the HLS of petroleum and manufactured goods price shocks are permanent. Shocks to the import unit value index and export unit value index have HLS which are both permanent, while the median HLS to Uganda's NBTT typically last just over 12 quarters. We find that the persistence of shocks to the prices of individual Ugandan commodities is very similar to that found in Cashin, Liang and McDermott (1999), which analyzed the persistence of shocks to world commodity prices using the International Monetary Fund's monthly International Financial Statistics (IFS) data. In Cashin, Liang and McDermott (1999), shocks to petroleum and coffee prices were found to be permanent, while of the remaining commodities examined above, only tobacco and maize have HLS which are significantly different (at the five percent level) from the persistence of shocks to Ugandan tobacco and maize (in that the 90 percent confidence interval of the HLS for the world commodity price does not overlap with the 90 percent confidence interval of the estimated HLS for its Ugandan counterpart).

Permanent shocks to Uganda's export unit value index are consistent both with the large weight of coffee in the index, and the generally longer persistence of aggregate indices. Shocks to both the export and import unit value indices are permanent, while shocks to the NBTT, or the ratio of these unit value indices, are finitely persistent. This pattern could result if the two non-stationary price series are cointegrated.

${ }^{37}$ For Uganda, all nominal indices are in U.S. dollars per kilogram, except for: other exports, export unit value, petroleum imports, import unit value and the terms of trade, which all are indices with base year 1991=100. The manufacturing unit value (MUV) index is a unit value index of exports from 20 industrial countries--use of the MUV index as a deflator is common to most studies in the commodity price literature (see Cashin, Liang and McDermott (1999)).

Between 1966:1-1998:2, the share of each commodity in the export unit value index was: coffee (70 percent), copper (2), cotton (8), hides (1), maize (2), tea (5), tobacco (1), other (11); the share of each commodity in the import unit value index was: petroleum (19), manufactures (proxied by the MUV index, 81). We thank Mark Henstridge for providing the Ugandan data. 


\section{Persistence of Terms of Trade Shocks-Alternative Data}

As a further check of the robustness of our results for the persistence of shocks to the NBTT, we examined the persistence of shocks using terms of trade data drawn from alternative sources - the World Bank's African Development Indicators (ADI) and the International Monetary Fund's International Financial Statistics (IFS). ${ }^{38}$ The results from 26 countries comparing the WDI and ADI data reveal that there are no cases where there is a statistically significant (at the 5 percent level) difference in the estimated HLS to the NBTT derived from each of the data. For all countries, the 90 percent confidence interval for the HLS to its NBTT as measured by the WDI data overlaps with the 90 percent confidence interval for the HLS to its NBTT as measured by the ADI data.

The results from the IFS data reveal that the duration (in years) of the estimated HLS to each country's NBTT is: Burkina Faso (2.677), Kenya (2.219), Malawi (1.246), Mauritius (4.434) and South Africa (permanent). For none of these five countries is the difference between the HLS as measured by the World Bank's WDI database and the International Monetary Fund's IFS database statistically significant (at the five percent level), as the 90 percent confidence interval for the HLS to each country's NBTT as measured by each data set always overlap.

38 The 26 Sub-Saharan African countries in the ADI sample are those listed in Appendix II, excepting Angola, Botswana, Comoros, Congo, Dem. Rep., Equatorial Guinea, Ethiopia, Guinea, Guinea-Bissau, Liberia, Mozambique, São Tomé and Principe, Seychelles, Somalia, Sudan, Tanzania, Togo, Uganda and Zimbabwe, which have been deleted due to a lack of data; the ADI data also includes two countries excluded from the WDI data of Table 1Lesotho and Swaziland. The data for all countries run from 1970-97, excepting: Lesotho and Sierra Leone (1970-96). The data are expressed in logarithmic form. The five countries in the IFS sample (and the sample period) are: Burkina Faso (1966-96), Kenya (1960-96), Malawi (1967-89), Mauritius (1961-98) and South Africa (1960-96). 
Cointegration and Unit Root Tests, Export and Import Price Indices, Sub-Saharan Africa, 1960-96

\begin{tabular}{|c|c|c|c|c|c|c|c|}
\hline \multirow{2}{*}{$\begin{array}{l}\text { Country } \\
\text { (1) }\end{array}$} & \multirow{2}{*}{$\begin{array}{c}\text { Cointegrating } \\
\text { Parameter } \\
(2)\end{array}$} & \multirow{2}{*}{$\begin{array}{l}Z(t) \\
(3)\end{array}$} & \multirow{2}{*}{$\begin{array}{l}\text { LC } \\
\text { (4) }\end{array}$} & \multirow{2}{*}{$\begin{array}{c}\text { Mean-F } \\
\text { (5) }\end{array}$} & \multirow{2}{*}{$\begin{array}{l}\text { Sup-F } \\
(6) \text {. }\end{array}$} & \multicolumn{2}{|c|}{$\begin{array}{c}\text { Phillips-Perron } \\
\text { Tests }\end{array}$} \\
\hline & & & & & & (7) & $(8)$ \\
\hline Angola & $1.524(0.121)$ & -1.655 & 0.29 & $4.67^{*}$ & $12.49^{*}$ & -1.455 & -1.305 \\
\hline Benin & $0.634(0.028)$ & -4.362 & $* 0.19$ & $4.70^{*}$ & $16.79^{*}$ & -1.591 & -3.484 \\
\hline Burkina Faso & $0.793(0.036)$ & -3.353 & 0.09 & 1.12 & 4.90 & -2.003 & -2.856 \\
\hline Cameroon & $0.875(0.075)$ & -1.599 & 0.27 & $7.41^{*}$ & $21.99^{*}$ & -1.421 & -1.835 \\
\hline Central African Rep. & $1.083(0.040)$ & -3.498 & $*_{0} 0.31$ & 3.92 & 6.61 & $-3.156^{*}$ & -3.393 \\
\hline Chad & $1.107(0.028)$ & -2.889 & 0.27 & 2.25 & 4.30 & -1.636 & -2.950 \\
\hline Congo, Dem. Rep. & $0.655(0.063)$ & -2.487 & 0.28 & $5.81^{*}$ & $23.20^{*}$ & -1.048 & -2.380 \\
\hline Congo & $1.567(0.143)$ & -2.471 & 0.29 & $11.77^{*}$ & $36.61^{*}$ & -1.775 & -2.097 \\
\hline Côte d'Ivoire & $0.889(0.060)$ & -1.694 & 0.28 & $4.58^{*}$ & $13.13^{*}$ & -1.369 & -1.937 \\
\hline Ethiopia & $0.521(0.083)$ & -2.231 & 0.26 & 4.04 & $13.01^{*}$ & -0.897 & -3.013 \\
\hline Gabon & $1.736(0.179)$ & -2.023 & 0.40 & $7.63^{*}$ & $16.85^{*}$ & -1.489 & -1.676 \\
\hline Gambia & $0.778(0.049)$ & -2.840 & 0.21 & $4.67^{*}$ & 11.88 & $-2,073$ & -3.073 \\
\hline Ghana & $0.753(0.095)$ & -1.825 & 0.29 & $9.94^{*}$ & $22.99^{*}$ & -1.501 & -2.109 \\
\hline Kenya & $0.808(0.059)$ & -1.684 & 0.27 & $13.81 *$ & $21.10^{*}$ & -1.127 & -2.550 \\
\hline Liberia & $0.541(0.027)$ & -5.728 & $* 0.26$ & 3.53 & $14.28 *$ & $-3.158^{*}$ & -2.827 \\
\hline Madagascar & $0.726(0.056)$ & -2.505 & 0.27 & 4.29 & 8.25 & -1.402 & -3.128 \\
\hline Malawi & $0.769(0.030)$ & -2.969 & 0.24 & 2.35 & 6.68 & -1.821 & $-3.529 *$ \\
\hline Mali & $1.035(0.023)$ & $-3.372^{*}$ & 0.26 & $10.98^{*}$ & $25.95^{*}$ & $-3.243^{*}$ & -3.461 \\
\hline Mauritania & $0.511(0.025)$ & -3.335 & 0.19 & $4.69^{*}$ & $12.74^{*}$ & -1.144 & -1.923 \\
\hline Mauritius & $1.042(0.072)$ & -2.494 & 0.30 & 3.06 & 5.88 & -2.445 & -2.529 \\
\hline Mozambique & $0.981(0.025)$ & -3.177 & 0.24 & 4.22 & 7.97 & $-3.120^{*}$ & -3.125 \\
\hline Niger & $0.523(0.030)$ & -3.434 & $* 0.10$ & 1.89 & 5.22 & -0.625 & -2.509 \\
\hline Nigeria & $1.785(0.210)$ & -1.410 & 0.43 & $7.19^{*}$ & $13.60^{*}$ & -1.312 & -1.154 \\
\hline Rwanda & $0.814(0.113)$ & -1.387 & 0.25 & $6.73^{*}$ & $22.82^{*}$ & -1.054 & -1.774 \\
\hline Senegal & $0.997(0.028)$ & -3.267 & 0.12 & 3.10 & $27.09^{*}$ & $-3.267^{*}$ & -3.269 \\
\hline Sierra Leone & $0.740(0.034)$ & -2.330 & 0.27 & $4.69^{*}$ & 9.52 & -0.973 & -2.834 \\
\hline Somalia & $0.679(0.022)$ & -3.529 & $* 0.20$ & 2.50 & 5.73 & -0.980 & -3.118 \\
\hline Sudan & $0.961(0.029)$ & -1.895 & 0.25 & $5.37^{*}$ & $21.77^{*}$ & -1.769 & -2.052 \\
\hline Tanzania & $0.794(0.072)$ & -1.642 & 0.25 & $4.72 *$ & 9.96 & -0.881 & -2.217 \\
\hline Togo & $0.774(0.101)$ & -2.450 & 0.31 & $9.70^{*}$ & $26.56^{*}$ & -2.168 & -2.703 \\
\hline Uganda & $0.685(0.152)$ & -1.534 & 0.26 & $5.30^{*}$ & $13.36^{*}$ & -1.086 & -1.933 \\
\hline Zambia & $0.486(0.093)$ & -2.683 & 0.22 & 4.22 & $15.11^{*}$ & -1.146 & -2.385 \\
\hline $\begin{array}{l}\text { Notes: The nominal exp } \\
1987=100 \text {, excepting: B } \\
\text { expressed in logarithmic } \\
\text { cointegrating regression } \\
\text { (1990)); the asymptotica } \\
\text { value for the residual-ba } \\
\text { critical values for the Ha } \\
\text { unit root tcsts of Phillips } \\
\text { constant (column (7)) an } \\
\text { and }-3.50 \text {, rcspectively. }\end{array}$ & $\begin{array}{l}\text { the export price } \\
\text {-correct standard } \\
\text { unit (1992) stabilit } \\
\text { d Perron (1988) }\end{array}$ & error of $t$ & Mits & and sup-F & $\begin{array}{l}\text { es. Colun } \\
\text { 0)) Colu } \\
.58,4.57\end{array}$ & $\begin{array}{l}\text { illips and } \\
\text { c } 5 \text { percen } \\
\text { : the } 5 \text { pe } \\
\text { respectiv }\end{array}$ & $\begin{array}{l}\text { base year } \\
\text { V) are } \\
\text { dificd } \\
\text { d Hansen } \\
\text { nt critical } \\
\text { ercent } \\
\text { vely. The } \\
\text { with a } \\
-2.93\end{array}$ \\
\hline
\end{tabular}




\section{DATA DEFINITIONS AND SOURCES}

Persistence of shocks to price of main commodity (ALCOM). Main commodities are identified from World Bank (1993) (based on UNCTAD), which provides the share of individual commodities in total exports averaged during 1985-87. This is close to the middle of our 1960-96 period used to estimate terms of trade shock persistence. This data is supplemented by Deaton (1999), which shows the main commodities in 1990. Commodity price shock persistence is the median-unbiased estimate of $\alpha$ from Cashin, Liang and McDermott (1999). If over 50 percent of a country's exports are accounted for by a commodity that was not in the Cashin et al. (1999) sample, the country is dropped from the regression (for example, Botswana: diamonds; Guinea: bauxite; and Niger: uranium).

Share of top three commodities in total commodity exports (TOP3), and world market share of top 3 commodity exports (BIGX). Taken from World Bank (1993), average of 1985-87.

Share of petroleum imports in total imports (OLM). Taken from the United Nations COMTRADE database, average of values in 1980 and 1990. Since many African countries fail to report data to the U.N. and statistics that are available may be of poor quality, we follow Yeats (1998) and use exports of petroleum to individual African countries by all their supplier countries to measure petroleum imports.

Dummy for fixed exchange rate regime (DFIXED). Taken from Ghosh et al. (1997), value in 1985.

Share of commodity exports in total exports (COMSH). Taken from World Development Indicators (WDI) 1999 database. Sum of agricultural raw materials exports, ores and metals exports, food exports and fuel exports, averaged during 1980-90.

Share of nonfuel commodity exports in total exports (NONFUEL). As above, excluding fuel exports.

Demand proxy: trade-weighted persistence of real GDP shocks of top 3 trading partners (ALTRADE). Trade weights are from the IMF's Information Notice System weights used to construct real effective exchange rates. Weights are averages for 1980-82, except for Angola which is 1988-90. Real GDP data of trading partners for the period 1960-96 is taken from the World Bank's WDI database (except for Germany, which is taken from the IMF's IFS). We calculated median-unbiased estimates of persistence of shocks to each country's GDP, and formed an overall index using the trade weights.

Share of manufactured goods imports in total imports (MANM). From United Nations COMTRADE database, average of 1980 and 1990 . Using partner country export statistics, as described above.

Dummy for CFA countries (DCFA). The CFA franc zone is comprised of Benin, Burkina Faso, Cameroon, Central African Republic, Comoros, Côte d'Ivoire, Chad, Equatorial Guinea, Gabon, Niger, Mali, Republic of Congo, Senegal and Togo.

Dummy for oil-exporters (DOIL). Angola, Cameroon, Republic of Congo, Equatorial Guinea, Gabon and Nigeria.

Size of shock (SIZE). Standard error of each country's NBTT regression of equation (1). 
COUNTRY ABbREVIATIONS

Angola (AGO)

Benin (BEN)

Botswana (BWA)

Burkina Faso (BFA)

Burundi (BDI)

Cameroon (CMR)

Central African Rep. (CAF)

Chad (TCD)

Comoros (COM)

Congo Dem. Rep. of (COD)

Congo, Republic of (COG)

Côte d'Ivoire (CIV)

Equatorial Guinea (GNQ)

Ethiopia (ETH)

Gabon (GAB)

Gambia, The (GMB)

Ghana (GHA)

Guinea (GIN)

Guinea-Bissau (GNB)

Kenya (KEN)

Liberia (LBR)

Madagascar (MDG)

Malawi (MWI)

Mali (MLI)

Mauritania (MRT)

Mauritius (MUS)

Mozambique (MOZ)

Niger (NER)
Nigeria (NGA)

Rwanda (RWA)

São Tomé and Principe (STP)

Senegal (SEN)

Seychelles (SYC)

Sierra Leone (SLE)

Somalia (SOM)

South Africa (ZAF)

Sudan (SDN)

Tanzania (TZA)

Togo (TGO)

Uganda (UGA)

Zambia (ZMB)

Zimbabwe (ZWE) 


\section{REFERENCES}

Andrews, Donald, 1991, "Heteroskedasticity and Autocorrelation Consistent Covariance Matrix Estimation," Econometrica, Vol. 59, pp. 817-88.

, 1993, "Exactly Median-Unbiased Estimation of First-Order Autoregressive/Unit Root Models," Econometrica, Vol. 61, pp. 139-65.

and Hong-Yuan Chen, 1994, "Approximately Median-Unbiased Estimation of Autoregressive Models," Journal of Business and Economic Statistics, Vol. 12, pp. 187-204.

Berg, Andrew and Christian Broda, 1999, "Do Floating Exchange Rate Regimes Buffer Terms-of-Trade Shocks in Developing Countries?," mimeo, (Washington: International Monetary Fund).

Bidarkota, Prasad and Mario Crucini, 1997, "Commodity Prices and the Terms of Trade," Ohio State University Working Paper 98-01, (Ohio State University).

Bleaney, Michael and David Greenaway, 1993, "Long Run Trends in the Relative Price of Primary Commodities and in the Terms of Trade of Developing Countries," Oxford Economic Papers, Vol. 45 , pp. 349-63.

Brooks, Ray, Mariano Cortes, Francesca Fornessari, Benoit Ketchemkmen, Ydahlia Metzgen, Robert Powell, Squib Rizavi, Doris Ross, and Kevin Ross, 1998, "External Debt Histories of Ten Low-Income Developing Countries: Lessons from Their Experience," IMF Working Paper 98/72, (Washington: International Monetary Fund).

Cashin, Paul, Hong Liang and C. John McDermott, 1999, "How Persistent Are Shocks to World Commodity Prices?," Working Paper WP/99/80 and forthcoming, IMF Staff Papers, (Washington: International Monetary Fund).

, C. John McDermott and Alasdair Scott, 1999, "Booms and Slumps in World Commodity Prices," Working Paper WP/99/155, (Washington: International Monetary Fund).

Hong Liang and C. John McDermott, 2000, "The Long-Run Behavior of Primary Commodity Prices," IMF Working Paper (forthcoming).

Cheung, Yin-Wong, Menzie D. Chinn and Eiji Fujii, 1999, "Market Structure and the Persistence of Sectoral Real Exchange Rates," Working Paper 7408, (Cambridge: National Bureau of Economic Research).

Cochrane, John H., 1988, "How Big Is the Random Walk in GNP?," Journal of Political Economy, Vol. 96 , pp. $893-920$.

Collier, Paul, Jan Gunning and Associates, 1999, Trade Shocks in Developing Countries, (Oxford, UK: Oxford University Press). 
Cuddington, John T. and Carlos M. Urzúa, 1989, "Trend and Cycles in the Net Barter Terms of Trade: A New Approach," Economic Journal, Vol. 99, pp. 426-42.

DeJong, David N,, John C. Nankervis, N.E. Savin and Charles H. Whiteman, 1992, "Integration Versus Trend Stationarity in Time Series," Econometrica, No. 60, pp. 423-33.

Deaton, Angus S., 1992, "Commodity Prices, Stabilization, and Growth in Africa," Research Program in Development Studies, Discussion Paper 166, Princeton University.

, 1999, "Commodity Prices and Growth in Africa," Journal of Economic Perspectives, Vol. 13, No. 3 , pp. 23-40.

and Guy Laroque, 1992, "On the Behaviour of Commodity Prices," The Review of Economic Studies, Vol. 59, pp. 1-24.

and Ron Miller, 1996, "International Commodity Prices, Macroeconomic Performance and Politics in Sub-Saharan Africa," Journal of African Economies, Supplement to Vol. 5, No. 3, pp. 99191.

Dickey, David A. and Wayne A. Fuller, 1979, "Distribution of the Estimators for Autoregressive Time Series with a Unit Root," Journal of the American Statistical Association, Vol. 74, pp. 427-31.

Ghosh, Atish, Anne-Marie Gulde, Jonathan Ostry and Holger Wolf, 1995, "Does the Nominal Exchange Rate Regime Matter?" IMF Working Paper 95/121 (Washington: International Monetary Fund).

Grilli, Enzo R. and Maw C. Yang, 1988, "Primary Commodity Prices, Manufactured Goods Prices, and Terms of Trade of Developing Countries: What the Long Run Shows, "World Bank Economic Review, Vol. 2, pp. 1-48.

Hansen, Bruce E., 1992, "Tests for Parameter Instability in Regressions with I(1) Processes, " Journal of Business and Economic Statistics, Vol. 10, pp. 321-35.

Hoffmaister, Alexander W., Jorge E. Roldos and Peter Wickham, 1998, "Macroeconomic Fluctuations in Sub-Saharan Africa," IMF Staff Papers, Vol. 45 (March). pp. 132-60 (Washington: International Monetary Fund).

International Monetary Fund, 1999, International Financial Statistics, (Washington: International Monetary Fund).

Kendall, Maurice and Alan Stuart, 1958, The Advanced Theory of Statistics, (New York: Hafner).

León, Javier and Raimundo Soto, 1995, "Terminos de intercambio en America Latina: una cuantificacion del la hipotesis de Prebisch y Singer," El Trimestre Economico, Vol. 52, pp. 171-99. 
1997, "Structural Breaks and Long Run Trends in Commodity Prices," Journal of International Development, Vol. 9, pp. 347-66.

McDermott, C. John, 1994, Structural and Evolutionary Change in Econometric Models, unpublished Ph.D dissertation, Department of Economics, Yale University, (New Haven: Yale University).

Mendoza, Enrique, 1995, "The Terms of Trade, The Real Exchange Rate and Economic Fluctuations," International Economic Review, Vol. 36 (February), pp. 101-37.

Orcutt, Guy H., 1948, "A Study of the Autoregressive Nature of the Time Series Used for Tinbergen's Model of the Economic System of the United States, 1891-1932," Journal of the Royal Statistical Society, Series B, No. 10, pp. 1-48.

Osei, Barfour, 1999, "Primary Commodity Exports and the Benefits of Trade: Empirical Evidence for Sub-Saharan Africa," mimeo (Accra: University of Ghana).

Perron, Pierre, 1989, "The Great Crash, the Oil Price Shock, and the Unit Root Hypothesis," Econometrica, Vol. 57, pp. 1361-1401.

Phillips, Peter and Bruce Hansen, 1990, "Statistical Inference in Instrumental Variable Regression with I(1) Processes," Review of Economic Studies, Vol. 57, pp. 99-125.

and Samuel Ouliaris, 1990, "Asymptotic Properties of Residual-Based Tests for Cointegration," Econometrica, Vol. 58, pp. 165-93.

and Pierre Perron, 1988, "Testing for a Unit Root in Time Series Regression," Biometrika, Vol. 75 , pp. 335-46.

Powell, Andrew, 1991, "Commodity and Developing Country Terms of Trade: What Does the Long Run Show?," Economic Journal, Vol. 101, pp. 1485-1496.

Prebisch, Raúl, 1950, The Economic Development of Latin America and its Principal Problems, United Nations, Lake Success.

Rudebusch, Glenn D., 1992, "Trends and Random Walks in Macroeconomic Time Series: A Reexamination," International Economic Review, Vol. 33, pp. 661-80.

Senhadji, Abdelhak, 1997 "Sources of Debt Accumulation in a Small Open Economy," IMF Working Paper 97/146 (Washington: International Monetary Fund).

Singer, Hans W., 1950, "The Distribution of Gains Between Investing and Borrowing Countries," American Economic Review, Papers and Proceedings, Vol. 40, pp. 473-85.

Stock, James, 1991, "Confidence Intervals for the Largest Autoregressive Root in U.S. Macroeconomic Time Series," Journal of Monetary Economics, Vol. 28, pp. 435-59. 
Svedberg, Peter, 1991, "The Export Performance of Sub-Saharan Africa," Economic Development and Cultural Change, pp. 549-66.

United Nations Conference on Trade and Development (UNCTAD), 1996, Handbook of International Trade and Development Statistics (New York, NY: United Nations).

World Bank, 1993, Commodity Trade and Price Trends, 1989-9I Edition (Baltimore, MA: The Johns Hopkins University Press).

World Bank, 1999, World Development Indicators, (Washington: World Bank)

Yeats, Alexander, 1998, "Have Policy Reforms Influenced the Trade Performance of Sub-Saharan African Countries," mimeo, (Washington: World Bank).

Zar, Jerrold H., 1972, "Significance Testing of the Spearman Rank Correlation Coefficient," Journal of the American Statistical Association, Vol. 67, pp. 578-80.

Zivot, Eric and Donald Andrews, 1992, "Further Evidence on the Great Crash, the Oil Price Shock, and the Unit Root Hypothesis," Journal of Business and Economic Statistics, Vol. 10, pp. 251-70. 